\title{
Design and Synthesis of "Chloropicolinate Amides and Urea Derivatives" as Novel Inhibitors for Mycobacterium tuberculosis
}

\author{
Srihari Konduri, Dodda Bhargavi, Jyothi Prashanth, Vagolu Siva Krishna, Dharmarajan Sriram, \\ and Koya Prabhakara Rao*
}

Cite This: ACS Omega 2021, 6, 1657-1667

Read Online

ABSTRACT: A series of 30 novel diamino phenyl chloropicolinate fettered carboxamides, urea, and thiourea derivatives were synthesized by coupling of methyl 4-amino-6-(2-aminophenyl)-3chloropyridine-2-carboxylate with different acid chlorides, urea, and thiourea moieties, respectively. All of these compounds were characterized by ${ }^{1} \mathrm{H}$ and ${ }^{13} \mathrm{C}$ nuclear magnetic resonance spectroscopy, $\mathrm{CHN}$ analysis, and high-resolution mass spectra for confirmation of the structures. Two compounds were also characterized by single-crystal X-ray diffraction analysis to confirm the structures obtained by spectral analysis. All these 30 compounds were tested for their in vitro antimycobacterial activity using the microplate alamar blue assay method against

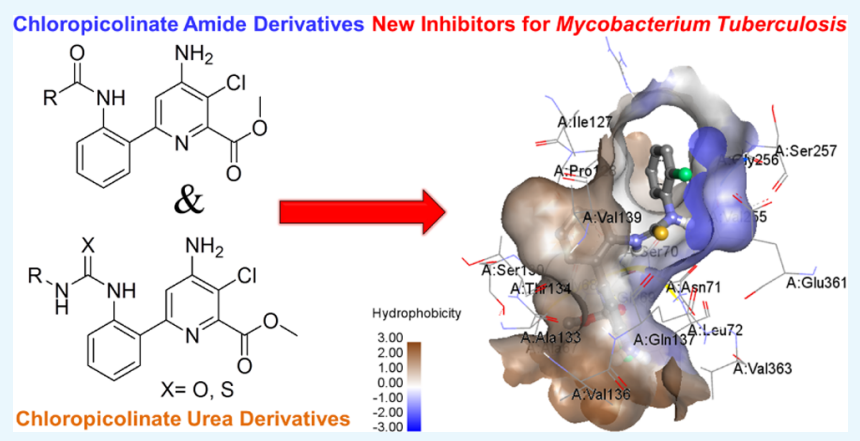
Mycobacterium tuberculosis. Five compounds have shown good minimum inhibitory concentration (MIC) values with low cytotoxicity when compared with the reference drugs. Moreover, some of the compounds have high MIC values compared with isoniazid, rifampicin, and so forth and also had shown good reign in the spread of bacteria by the nutrient starvation model. These antimycobacterial activity results have shown a good correlation with molecular docking model analysis with the inhibitors MurB by exhibiting strong interactions. Some of these compounds could be promising candidates against $M$. tuberculosis for future preclinical agent drug development.

\section{INTRODUCTION}

Tuberculosis (TB) is one of the most common infectious and deadliest diseases ${ }^{1-8}$ caused by a family of Mycobacteriaceae pathogenic bacteria. The spread of TB disease caused by a single infectious bacteria resulted in a large number of deaths throughout the world, ${ }^{5}$ as per the World Health Organization (WHO) report of 2017. Recently, TB has emerged as resistant to existing antibiotics ${ }^{9,10}$ at various levels of the drugs including drug-resistant tuberculosis, extremely drug-resistant tuberculosis, multidrug-resistant tuberculosis, and total drugresistant tuberculosis. In this context, new anti-TB drugs are desired and many are in various phases of their development. ${ }^{11}$ First-line drugs such as rifampicin and isoniazid are at present best-practice therapy drugs for the treatment of TB within 6 months. Indeed, in these two drugs, heterocyclic moieties play a crucial role in affecting new acquirement. ${ }^{12,13}$ Moreover, the isonicotinamide moiety-related heterocyclic compound based anti-TB drugs such as isoniazid ${ }^{14}$ and ethionamide, ${ }^{15}$ have been reported in the literature.

Chloropicolinate amide and urea derivatives are well known as excellent herbicides. ${ }^{16,17}$ Recently, highly potent 6arylpicolinate herbicides, including 5 DAS-534, Arylex active, and Rinskor active, have been developed. ${ }^{18}$ In fact, Rinskor and Arylex were commercially launched and exhibited very good control of broadleaf weeds. In the above herbicides, ${ }^{16-18}$ the chloropicolinate amide heterocyclic moiety plays a crucial role in reducing weeds without affecting the immune system of the plants for maximum crop production. In fact, keeping in mind the above two important heterocyclic moieties such as the isonicotinamide moiety for anti-TB activity and chloropicolinate amide moiety for reducing unwanted bacterial growth without affecting the human immune system, we were interested to develop a new heterocyclic scaffold by mimicking the above two moieties in a single moiety for better anti-TB activity (Figure 1).

It is well known that, recently, TB has emerged as resistant to existing antibiotics due to the drug-resistant Mycobacteriaceae pathogenic bacteria. ${ }^{9,10}$ Moreover, some of the anti-TB drugs are affecting human immunity systems along with killing Mycobacteriaceae pathogenic bacteria. In this context, we were interested to develop new chloropicolinate analogues as

Received: November 23, 2020

Accepted: December 28, 2020

Published: January 7, 2021 

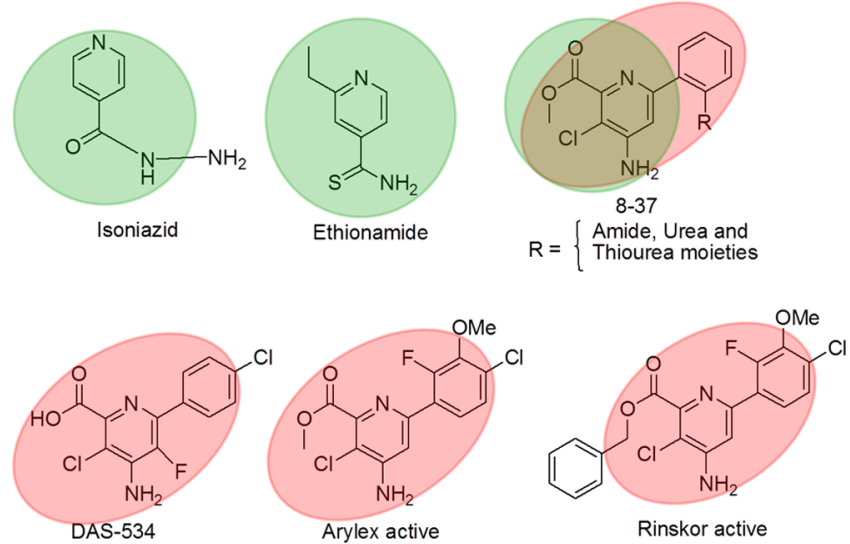

Figure 1. Isonicotinamide moiety-related anti-TB drugs, isoniazid and ethionamide, along with titled compounds 8-37 (top) and chloropicolinate moiety-related various herbicides (bottom).

possible new inhibitors and more adequate anti-TB drugs against all forms of Mycobacterium tuberculosis (MTB) without affecting the human immune system (Figure 1). With this strategy, we designed 30 new heterocyclic scaffolds that could be synthesized by treating methyl 4-amino-6-(2-aminophenyl)3-chloropyridine-2-carboxylate with different acid chloride, urea, and thiourea moieties. Besides, one of the major research area for our group is to design and synthesize a new heterocyclic scaffold containing compounds for novel biological activity and material applications. ${ }^{8,19-26}$

In this report, we focused on the synthesis, characterization, and antimycobacterial activity against $M$. tuberculosis (Mtb) $\mathrm{H} 37 \mathrm{Rv}$ of 30 new compounds, methyl 4-amino-6-(2-aminophenyl)-3-chloropicolinate amide (8-26) derivatives and related urea and thiourea derivatives $(27-37)$, respectively. Indeed, chloropicolinate amide and urea derivatives are known as good herbicide active agents ${ }^{16,17}$ in the literature, which are commonly toxic in nature. In this context, all these 30 derivatives, $(8-37)$, were studied for their cytotoxicity determination to assess the toxicity of the compounds against normal host cells (macrophages) and found that all of the derivatives were exhibiting nontoxic behavior. Based on our present study, we could conclude that a therapeutic window is apparent, which is a roadmap for the design and development of this class of compounds as future anti-TB drugs.

\section{RESULTS AND DISCUSSION}

Syntheses. The synthetic routes for the syntheses of methyl 4-amino-6-(2-aminophenyl)-3-chloropicolinate amides $(8-26)$, related urea, and thiourea derivatives $(27-37)$ are outlined in Scheme 1. In the first step, the reaction of 3,6dichloropyridine-2-carboxylic acid ${ }^{27}$ with $\mathrm{HBr}$ in acetic acid afforded the 6-bromo-3-chloropyridine-2-carboxylic acid ${ }^{11}$ (2). In the second step, 2 reacted with methanol and sulfuric acid to afford the corresponding methyl 6-bromo-3-chloropyridine2-carboxylate ${ }^{28}$ (3). Later, compound 3 reacted with $\mathrm{H}_{2} \mathrm{O}_{2}$ in the presence of trifluoroacetic acid and trifluoroacetic anhydride to offer an intermediate compound ${ }^{29}$ (4). In the fourth step, compound 4 reacted with nitric acid and sulfuric acid to offer another intermediate compound $(5){ }^{28}$ Similarly, 5 reacted with Raney-Ni under a hydrogen atmosphere to offer the compound $\mathbf{6}$. In the sixth step, the compound 6 reacted with 2-amino phenyl boronic acid, $\mathrm{Pd}(\mathrm{II}) \mathrm{Cl}_{2}(\mathrm{dppf})$, and $\mathrm{K}_{2} \mathrm{CO}_{3}$ reagents via Suzuki-Miyaura coupling reaction and
Scheme 1. Synthesis of Methyl 4-Amino-6-(2aminophenyl)-3-chloropicolinate Amide, Urea, and Thiourea Derivatives $^{a}$

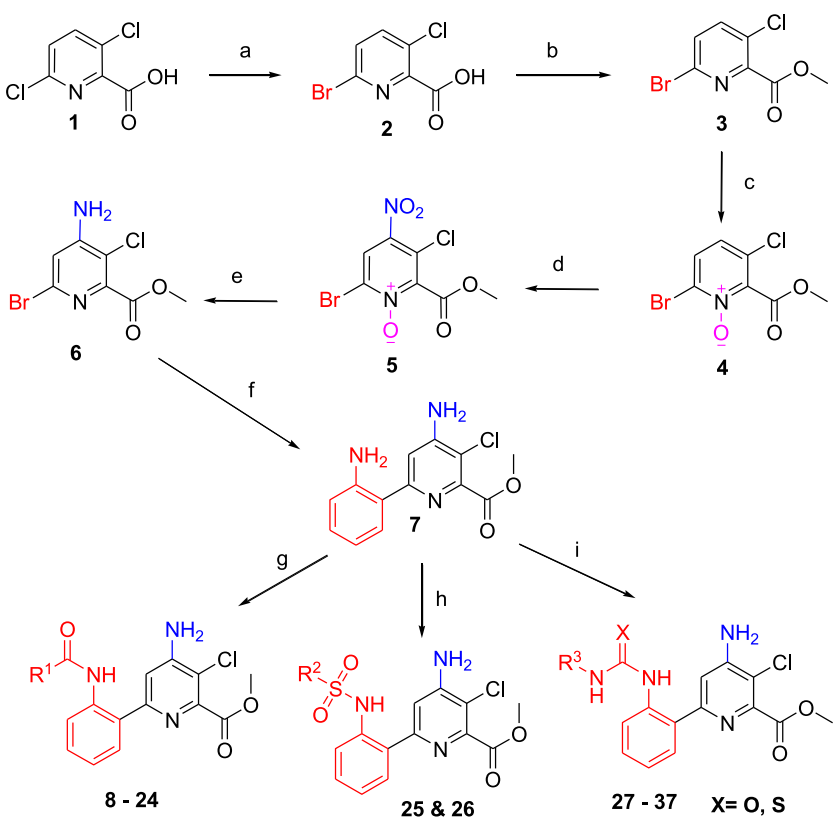

${ }^{a}$ Reagents and conditions: (a) $\mathrm{HBr}$ in acetic acid, $\mathrm{AcOH}, 110^{\circ} \mathrm{C}, 24$ h; (b) methanol, $\mathrm{H}_{2} \mathrm{SO}_{4}$, reflux, $6 \mathrm{~h}$; (c) trifluroacetic acid, TFAA, $\mathrm{H}_{2} \mathrm{O}_{2}, 80{ }^{\circ} \mathrm{C}, 3 \mathrm{~h}$; (d) $\mathrm{HNO}_{3}: \mathrm{H}_{2} \mathrm{SO}_{4}, 70{ }^{\circ} \mathrm{C}, 4 \mathrm{~h}$; (e) Raney Ni, $\mathrm{MeOH}, 45^{\circ} \mathrm{C}, \mathrm{H}_{2}, 8 \mathrm{~h}$; (f) $\mathrm{Pd}(\mathrm{II}) \mathrm{Cl}_{2}$ (dppf), $\mathrm{K}_{2} \mathrm{CO}_{3}, 2$-aminophenyl boronic acid, EtOH, toluene, $90^{\circ} \mathrm{C}$; (g) $\mathrm{R}^{1} \mathrm{COCl}$, DCM, $6 \mathrm{~h}, \mathrm{RT}$; (h) $\mathrm{R}^{2} \mathrm{SO}_{2} \mathrm{Cl}$, DIPEA, DCM, $3 \mathrm{~h}, \mathrm{RT}$; and (i) $\mathrm{R}^{3} \mathrm{NCO} / \mathrm{R}^{3} \mathrm{NCS}, \mathrm{DCM}$, TEA, 4 h, RT.

yielded the scaffold, methyl 4-amino-6-(2-aminophenyl)-3chloropyridine-2-carboxylate ${ }^{29}$ (7). In the final step, the coupling reaction of 7 , with three different moieties such as acid chlorides, isothiocyanates, and isocyanates, afforded respective amides 8-26, thiourea, and urea derivatives $27-$ 37 , respectively, in reasonably good yields (Scheme 1 ).

X-Ray Crystal Structure. All compounds (8-37) were characterized by ${ }^{1} \mathrm{H}$ and ${ }^{13} \mathrm{C}$ NMR spectroscopy, $\mathrm{CHN}$ analysis, and HR-MS (Supporting Information). However, in order to confirm the structures determined by the spectroscopic techniques, crystal growths were attempted with diffusion methods using different solvent combinations of acetonitrile/methanol, dichloromethane $/ n$-hexane, and dimethylformamide/methanol, and so forth. In fact, during our attempts, we could get good quality of the single crystals, which are suitable for single-crystal X-ray diffraction (SXRD) analysis for the compounds 15 and 18 . The SXRD structure (ORTEP) diagrams for these two compounds $\mathbf{1 5}$ and $\mathbf{1 8}$ are shown in Figure 2 (pertinent SXRD data provided in Table S1, Supporting Information). The structures obtained by SXRD confirmed the structures determined by spectral data. Compound 15 crystallizes in an orthorhombic system with space group $\mathrm{Pbca}$. The asymmetric unit contains one formula unit $\left(\mathrm{C}_{20} \mathrm{H}_{14} \mathrm{ClF}_{3} \mathrm{~N}_{4} \mathrm{O}_{3}\right)$ without any solvent of crystallization. Moreover, it shows two types of $\mathrm{H}$-bonding, intramolecular $\mathrm{H}$ bond between $\mathrm{N}(3) \cdots \mathrm{H}(1)-\mathrm{N}(2)$ and intermolecular $\mathrm{H}$-bond between $\mathrm{O}(1) \cdots \mathrm{H}(1)-\mathrm{N}(2)$, with values of 2.740 and $2.971 \AA$, respectively. Similarly, compound $\mathbf{1 8}$ crystalizes in a monoclinic crystal system with space group $P 2_{1} / c$. The asymmetric unit contains one formula unit $\left(\mathrm{C}_{21} \mathrm{H}_{16} \mathrm{ClF}_{2} \mathrm{~N}_{3} \mathrm{O}_{4}\right)$ without any 

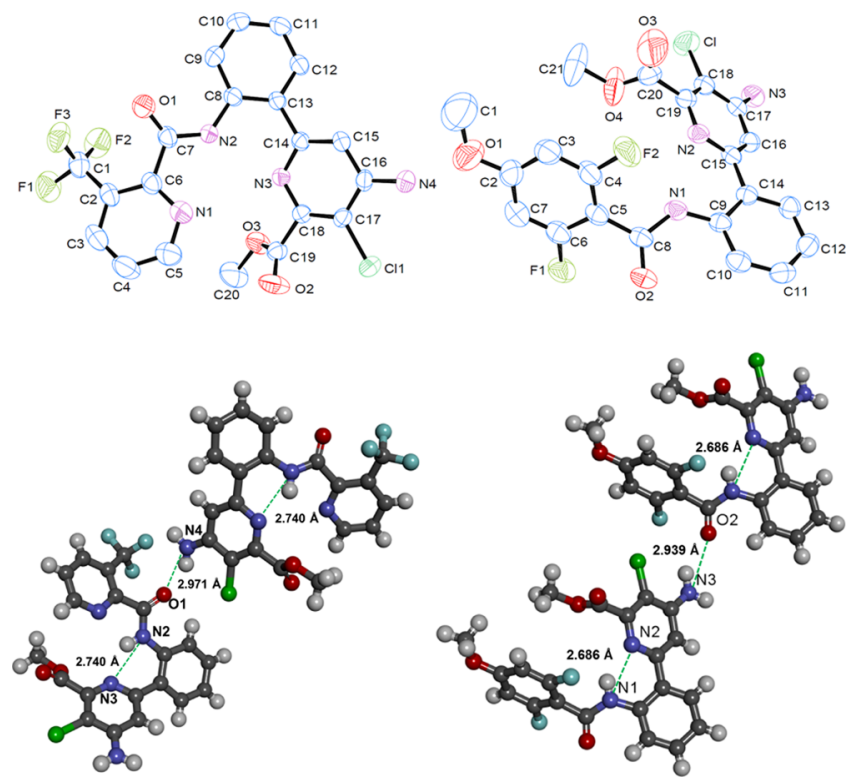

Figure 2. SXRD structures, ORTEP diagrams (50\% probability) (top) and their H-bonding network (bottom) of compounds 15 (left) and 18 (right), respectively.

solvent of crystallization. Compound 18, also shows two types of $\mathrm{H}$-bonding, intramolecular $\mathrm{H}$-bonding is between $\mathrm{N}(2) \cdots$ $\mathrm{H}(4)-\mathrm{N}(1)$ and intermolecular $\mathrm{H}$-bonding is between $\mathrm{O}(2) \cdots$
$\mathrm{H}(1)-\mathrm{N}(3)$, with values of 2.686 and $2.939 \AA$, respectively (Table 1).

In Vitro Antimycobacterial Activity. After success in the synthesis and structural confirmation of all these 30 compounds, 8-37, they were screened against their in vitro antimycobacterial activity against $M$. tuberculosis H37Rv (ATCC27294) by the microplate alamar blue assay (MABA) method. $^{30-34}$ The minimum inhibitory concentration (MIC) could be defined as the minimum concentration of the compound required for the entire inhibition of bacterial growth. The MIC values $(\mu \mathrm{M})$ of $8-37$ purposive in triplicate along with the standard compounds (reference drugs) for the comparison are listed in Table 2. All these 30 new compounds presented in vitro activity against $\mathrm{Mtb}$ varying from 6.96 to $68.96 \mu \mathrm{M}$. When compared to the first-line anti-TB drugs, majority of the compounds 8-37 are less powerful than isoniazid $(0.7 \mu \mathrm{M})$. However, five compounds, $16(6.96 \mu \mathrm{M})$, $19(6.98 \mu \mathrm{M}), 28(7.00 \mu \mathrm{M}), 22(7.86 \mu \mathrm{M})$, and $10(7.90$ $\mu \mathrm{M})$, showed good MIC values that are prominently exhibiting in vitro potency close to isoniazid and higher than ethambutol. Among the other compounds, 13, 14, 17, 18, 20, 21, 24, 29, 30, 31, and 32 are also promising candidates based on their MIC values reported in Table 2 for the inhibitors of Mtb.

The CLogP values for all compounds 8-37 are less than 5.0 due to the functional groups such as amide, urea, and thiourea of the scaffold and also the halogen of the other substituents. From these data, it is very clear that all compounds 8-37 have good permeation nature with hydrophilicity absorption,

Table 1. Syntheses of Methyl 4-Amino-6-(2-aminophenyl)-3-chloropicolinate Amide (8-26) Derivatives and Related Urea and Thiourea Derivatives (27-37), Respectively ${ }^{a}$

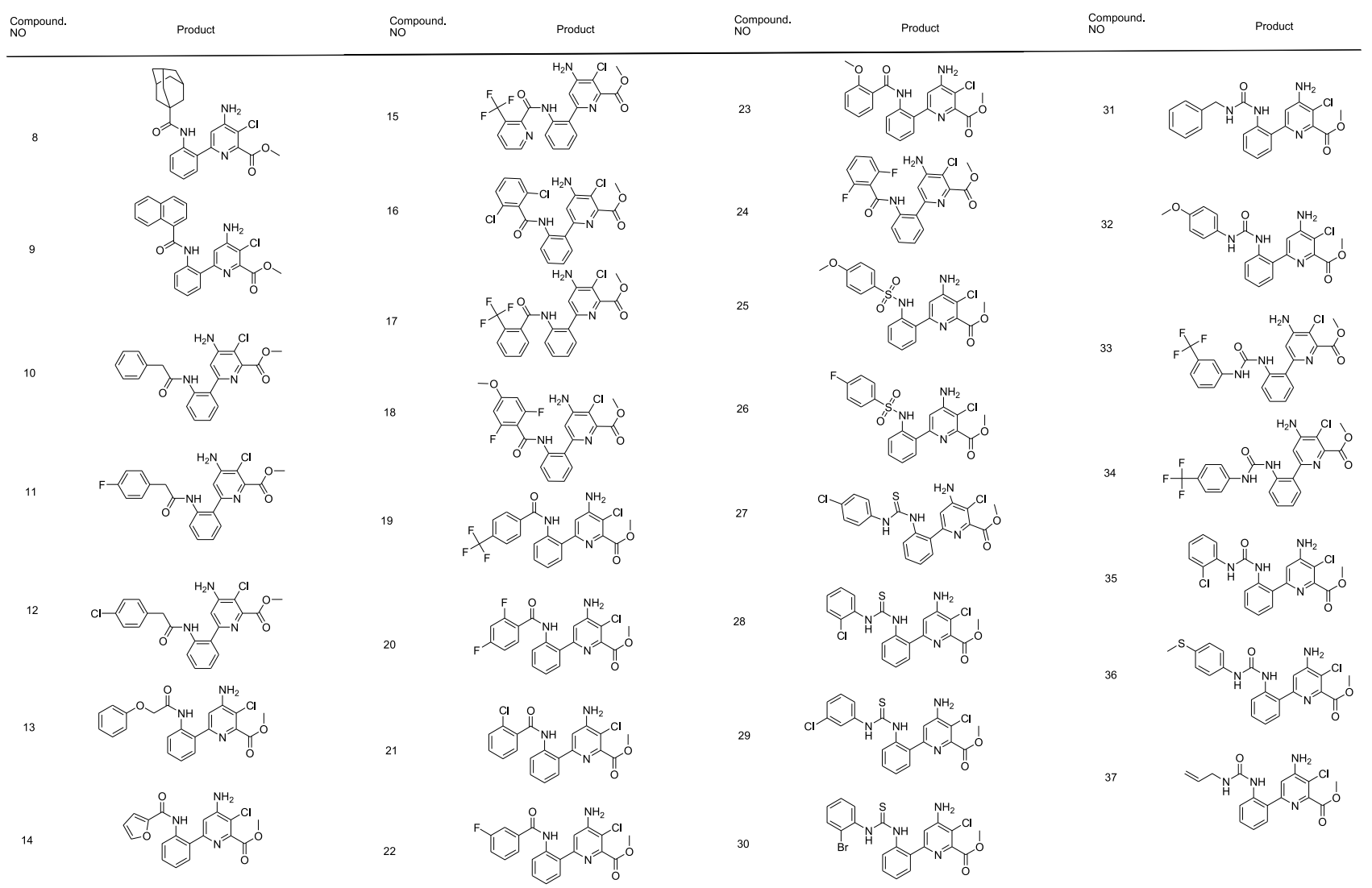

${ }^{a}$ All products were characterized by NMR spectroscopy and mass spectrometry. 
Table 2. Antimycobacterial Activity of 8-37 Compounds

\begin{tabular}{|c|c|c|c|c|c|}
\hline compd & $C \log P^{a}$ & $\operatorname{MIC}(\mu \mathrm{M})$ & compd & $C \log P^{a}$ & $\operatorname{MIC}(\mu \mathrm{M})$ \\
\hline 8 & 3.34 & 61.48 & 23 & 2.22 & 65.68 \\
\hline 9 & 3.35 & 57.98 & 24 & 1.76 & 14.98 \\
\hline 10 & 2.22 & 7.90 & 25 & 3.29 & 27.96 \\
\hline 11 & 2.36 & 30.25 & 26 & 3.45 & 68.96 \\
\hline 12 & 2.93 & 29.13 & 27 & 3.64 & 28.2 \\
\hline 13 & 2.20 & 15.20 & 28 & 3.8 & 7.00 \\
\hline 14 & 1.35 & 8.42 & 29 & 3.64 & 14.01 \\
\hline 15 & 1.40 & 57.76 & 30 & 3.23 & 12.75 \\
\hline 16 & 2.06 & 6.96 & 31 & 3.45 & 15.78 \\
\hline 17 & 2.09 & 13.92 & 32 & 3.57 & 14.67 \\
\hline 18 & 1.87 & 13.98 & 33 & 4.87 & 53.87 \\
\hline 19 & 3.30 & 6.98 & 34 & 4.87 & 62.49 \\
\hline 20 & 2.17 & 14.99 & 35 & 3.92 & 29.3 \\
\hline 21 & 2.15 & 15.06 & 36 & 4.15 & 28.27 \\
\hline 22 & 2.41 & 7.86 & 37 & 2.46 & 34.71 \\
\hline Isoniazid & & & & & 0.78 \\
\hline Ethambutol & & & & & 7.89 \\
\hline Rifampicin & & & & & 0.21 \\
\hline
\end{tabular}

though some of the compounds having high MIC values, with good hydrophilicity absorption or permeation character, could be potential candidates for anti-TB drugs. We observed that in some compounds such as $10,16,19$, and 28 , the halogen and other substituent groups could interact better with the protein acceptors by strong H-bonding ${ }^{33}$ (see Figure 3 of 19). On the other hand, in some compounds, such as $8,9,15,23,26,33$, and 34, shown high MIC values might be due to very rigid donor groups as substituents on the heterocyclic skeleton. In the structure activity correlation, various donor and acceptor abilities have driven substituted groups on the heterocyclic scaffolds and structural changes are very crucial in their diversified anti-TB activity of the titled compounds, 8-37. In fact, we designed the titled compounds with new heterocyclic scaffold by mimicking two different moieties such as the isonicotinamide moiety for anti-TB activity and chloropicolinate amide moiety for reducing unwanted bacterial growth without affecting the human immune system, exhibiting good anti-TB activities as per the assumption. Moreover, our cytotoxicity determination of lead compounds indicated that they are nontoxic to human cells similar to the herbicides to the desired plants. Besides, compounds 16 and 19 possessed the most promising anti-TB activity compared with other compounds of the present study. In these two compounds, more electronegative (acceptor) substitutes in the phenyl rings of the amide moiety increase the anti-TB activity due to the increase in the hydrophilicity (polarity) of the heterocyclic skeleton, which is similar to our recent report ${ }^{8}$ on new heterocyclic compounds based on novel inhibitors for Mtb.

Nutrient Starvation Model. Generally, at present the first-line drugs such as rifampicin and isoniazid are useful in eliminating the TB in humans in few months. However, these drugs could not reign in the spread of bacteria and deadly decease like highly sluggish TB. In fact, this phenomenon could lead to supplement and oxygen refuse conditions in humans. Perhaps, the supplement starvations aggravate a sluggish condition in the bacilli bacteria that rehabilitate it to a non-reproducing stage. In order to replicate this nonreproducing stage of the lifecycle, the Mtb culture was supplement starved in phosphate buffer saline over a period of 6 weeks. ${ }^{35,36}$ Later, this starved MTB culture was treated again with all compounds, 8-37 of the present study. Among all compounds, 10, 14, 16, 19, 22, and 28 with $10 \mu \mathrm{M}$ concentrations have shown $0,2.0,0,1.9,1.8$, and $1.8 \log$ devaluation in growth, respectively. Surprisingly, these results are better or similar to some of the first-line drugs such as moxifloxacin with a $2.0 \log$ reduction and rifampicin with a 1.8 $\log$ reduction (Figure 3 ).

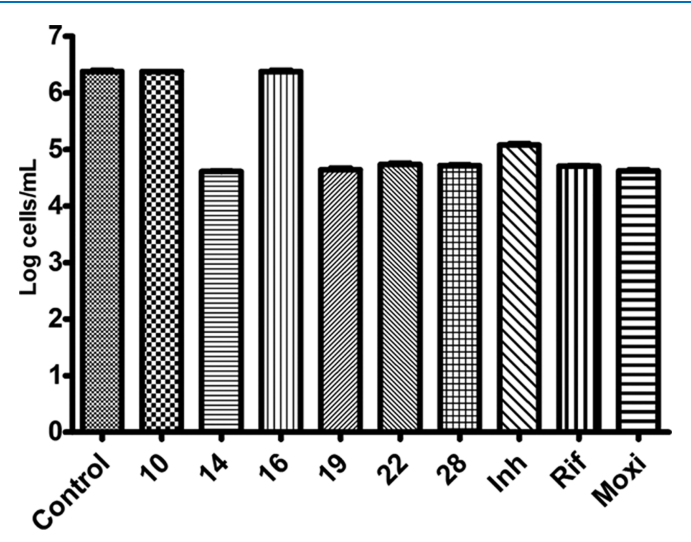

Figure 3. Activity profiles of some of the lead compounds (10, 14, 16, 19, 22, and 28) and known first-line TB drugs using the nutrient starvation model (NSM) model. The most probable number assay method was used to estimate the bacterial count, and the connotation plot was generated by adopting two-way ANOVA equations $(p<$ 0.0001 , using Graph-Pad prism software).

Cytotoxicity Determination. To estimate the toxicity of the lead compounds used for the NSM method ${ }^{35-37}$ against normal host cells such as macrophages, we carried out the MTT (3-(4,5-dimethylthiazol-2-yl)-2,5-diphenyltetrazolium bromide) assay procedure. The cytotoxicity determination was carried out at $25 \mu \mathrm{g} / \mathrm{mL}$ concentrations using the compounds showing better results in the NSM model (10, 14, 16, 19, 22, and 28). Among these compounds, 10 and 22 inhibit the growth of these cells by 22.4 and $14.9 \%$, respectively. However, both compounds have no inhibition observed at $10 \mu \mathrm{g}$ concentrations. Moreover, compounds 14, 16,19 , and 28 were found to be completely nontoxic in nature. Therefore, we can conclude that even at this prior stage of development of this class of compounds as anti-TB drugs, a therapeutic window is desirable for future drug development.

Molecular Docking Study. The molecular docking in silico studies of all compounds, 8-37, was carried out using $S$. areus MurB enzyme. ${ }^{38-40}$ MurB is a key enzyme that mobilizes the reduction of enolpyruvyl uridine diphosphate $\mathrm{N}$-acetyl glucosamine, an intermediate in the assembly of the uridine diphosphate $\mathrm{N}$-acetyl muramic acid (UNAM)-pentapeptide (m-A2pm) portion to UNAM, of the cell wall precursor. Mur proteins (Mur A-F, Y, and G) catalyze more than 10 biosynthetic transformations involved in the formation of peptidoglycan layer of the cell walls of bacteria and are also conserved among several bacterial strains. UDP- $N$-acetylglucosamine-enolpyruvate reductase (MurB) also plays an important part in the binding of EP-UDPGIcNAc or $\mathrm{NADPH}$ in Escherichia coil MurB. ${ }^{39}$ Due to this cause, we choose MurB enzyme as a target receptor. The respective docking parameters, such as binding energy values and number 
of $\mathrm{H}$ bonds and amino acid residue moieties involved in bonding against receptor reductase MurB, are listed in Table 3.

Table 3. Compounds 8-37, Molecular Docking in Silico Parameters Such as Binding Energy and Number of $\mathbf{H}$ Bonds and Residues Involved in Bonding against Receptor Reductase MurB

\begin{tabular}{|c|c|c|c|c|}
\hline \multirow[b]{3}{*}{$\begin{array}{l}\text { s. } \\
\text { no }\end{array}$} & \multirow[b]{3}{*}{ compound } & \multicolumn{3}{|c|}{ binding energies $\left(\mathrm{kcal} \mathrm{mol}^{-1}\right)$} \\
\hline & & \multicolumn{3}{|c|}{ Mtb MurB (PDB ID: 5JZX) } \\
\hline & & $\begin{array}{l}\text { binding } \\
\text { energy }\end{array}$ & $\begin{array}{l}\text { no. of } \\
\mathrm{H} \text { bonds }\end{array}$ & residues involved in bonding \\
\hline 1 & 8 & -8.83 & 03 & ASN71, SER70(2) \\
\hline 2 & 9 & -8.63 & 05 & $\begin{array}{l}\text { SER70(2), ASN71, SER130, } \\
\text { GLN137 }\end{array}$ \\
\hline 3 & 10 & -9.65 & 03 & SER70, SER254, THR26 \\
\hline 4 & 11 & -9.03 & 07 & $\begin{array}{l}\text { SER70, SER257, ARG238(3), } \\
\text { GLY140, GLU361 }\end{array}$ \\
\hline 5 & 12 & -9.19 & 03 & ASN71, SER70(2) \\
\hline 6 & 13 & -9.00 & 03 & SER70, GLY140(2) \\
\hline 7 & 14 & -9.35 & 04 & SER70, ASN71, GLY69, ALA67 \\
\hline 8 & 15 & -8.37 & 05 & $\begin{array}{l}\text { ARG238(2), GLY140, SER257, } \\
\text { VAL255 }\end{array}$ \\
\hline 9 & 16 & -9.59 & 02 & SER70, THR26 \\
\hline 10 & 17 & -9.01 & 03 & SER70, SER254, THR26 \\
\hline 11 & 18 & -9.05 & 03 & $\operatorname{SER}(2), \operatorname{ASN} 71$ \\
\hline 12 & 19 & -9.52 & 04 & $\begin{array}{l}\text { ASN71, ARG238, GLY69, } \\
\text { ALA67 }\end{array}$ \\
\hline 13 & 20 & -8.64 & 05 & $\begin{array}{l}\text { SER70, ASN71, GLY69(2), } \\
\text { GLY68 }\end{array}$ \\
\hline 14 & 21 & -8.95 & 04 & SER70(2), ASN71, GLY69 \\
\hline 15 & 22 & -10.86 & 04 & SER70(2), ASN71, GLY69 \\
\hline 16 & 23 & -8.50 & 04 & $\begin{array}{l}\text { GLY68, SER130, } \\
\text { ALA133,VAL65 }\end{array}$ \\
\hline 17 & 24 & -8.96 & 05 & $\begin{array}{l}\text { SER70(2), ASN71, GLY69, } \\
\text { GLY68 }\end{array}$ \\
\hline 18 & 25 & -8.68 & 04 & SER70(2), ASN71, VAL255 \\
\hline 19 & 26 & -8.55 & 05 & $\begin{array}{l}\text { SER254, ARG238, THR26, } \\
\text { VAL255, GLY140 }\end{array}$ \\
\hline 20 & 27 & -8.44 & 06 & $\begin{array}{l}\text { SER257(2), ARG238, ASN71, } \\
\text { SER70, VAL255 }\end{array}$ \\
\hline 21 & 28 & -9.54 & 05 & $\begin{array}{l}\text { ASN71(2), SER70, GLY69, } \\
\text { VAL255 }\end{array}$ \\
\hline 22 & 29 & -8.85 & 07 & $\begin{array}{l}\text { SER70(2), ARG238(3), } \\
\text { SER257, GLU361 }\end{array}$ \\
\hline 23 & 30 & -9.02 & 02 & SER70, ASN71 \\
\hline 24 & 31 & -9.07 & 04 & SER70, ASN71, GLY140(2) \\
\hline 25 & 32 & -8.79 & 03 & ASN71, ARG238, GLY140 \\
\hline 26 & 33 & -8.07 & 04 & SER70(2), VAL255(2) \\
\hline 27 & 34 & -8.68 & 03 & ASN70, ASN71, SER254 \\
\hline 28 & 35 & -9.07 & 04 & SER70(3), ARG238 \\
\hline 29 & 36 & -8.31 & 02 & GLN137, ASN71 \\
\hline 30 & 37 & -8.09 & 05 & SER70(3), ARG238, GLU361 \\
\hline
\end{tabular}

The results indicated that compound 22 exhibits the highest binding energy $-10.86 \mathrm{Kcal} / \mathrm{mol}$, containing $\mathrm{H}$-bonding with four amino acid residues SER70(2), ASN71, and GLY69 (Figure 4). Similarly, compounds $\mathbf{1 6}$ and 19 (Figure 4) have good binding energies of -9.59 and $-9.52 \mathrm{kcal} / \mathrm{mol}$ and $\mathrm{H}$ bonding with two (SER70 and THR26) and four (ASN71, ARG238, GLY69, and ALA67) amino acid residues, respectively. Antimycobacterial activity against $M$. tuberculosis $\mathrm{H} 37 \mathrm{Rv}^{8}$ (ATCC27294) (Table 2) also indicated that the compounds 16, 19, and 22 have shown good MIC values, in agreement with the docking results. Furthermore, in other compounds also, the hydrogen bonding interactions caused by

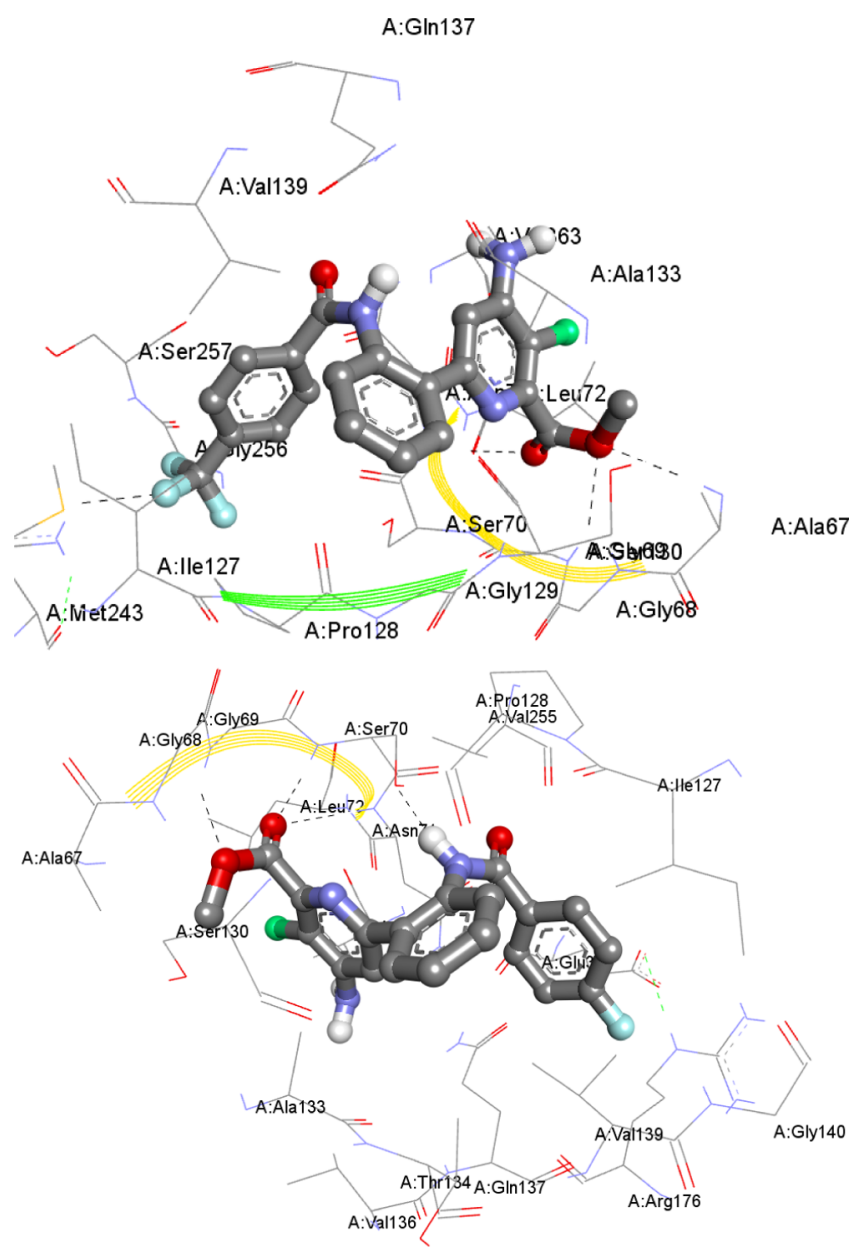

Figure 4. Molecular docking interactive profiles of the compounds, 19 (top) and 22 (bottom) (ball and stick model), showing their intermolecular H-bonding (dotted line) with the receptor UDP-Nacetylglucosamine-enol pyruvate reductase (MurB) protein and their various amino acid residues (stick model).

binding energies with the protein receptor found in molecular docking analysis were reasonably in good correlation with their respective antimycobacterial activity results.

\section{CONCLUSIONS}

A series of 30 new diamino phenyl chloropicolinate fettered carboxamides, urea, and thiourea derivatives were synthesized and characterized by ${ }^{1} \mathrm{H}$ and ${ }^{13} \mathrm{C}$ NMR spectroscopy, HR-MS, and $\mathrm{CHN}$ analysis for confirmation of the structures. Two compounds were also characterized by SXRD analysis to confirm the structures obtained by spectral analysis. All these compounds were tested for their in vitro antimycobacterial activity against $M$. tuberculosis. Five compounds (10, 16, 19, 22, and 28) have shown good MIC values with low cytotoxicity character. Moreover, these compounds have also shown good reign in the spread of bacteria by the NSM. The antimycobacterial activity results were also correlated with in silico molecular docking model analysis. The compounds have strong binding interactions with MurB inhibitor. The titled compounds with new heterocyclic scaffold by mimicking two different moieties such as the isonicotinamide moiety for antiTB activity and chloropicolinate amide moiety for reducing unwanted bacterial growth without affecting the human immune system exhibited good anti-TB activities. Moreover, 
electronegative (acceptor) substitutes in the phenyl ring moieties increase the anti-TB activity due to the increase in the hydrophilicity (polarity) of the heterocyclic skeleton. We believe that this study provides information about this new series of heterocyclic compounds, which would be potential candidates for the future development of new drugs for the treatment of Mtb and other antibacterial activity applications.

\section{EXPERIMENTAL SECTION}

General. Melting points were recorded using capillary tubes on an Elchem lab melting point apparatus for all compounds of this work, and the values reported were not corrected. Thinlayer chromatography was performed using $0.2 \mathrm{~mm}$ commercial silica gel plates (silica gel 60, F254, EMD Chemicals) and visualized with UV, an aqueous potassium permanganate $(\mathrm{KMnO} 4)$ stain. Nuclear magnetic resonance (NMR) spectra were recorded on a Varian $\left[{ }^{1} \mathrm{H}\right.$ NMR: DMSO (2.50) at $300 \mathrm{MHz}$ and $400 \mathrm{MHz} ;{ }^{1} \mathrm{H} \mathrm{NMR}: \mathrm{CDCl}_{3}$ (7.26) at $300 \mathrm{MHz}{ }^{13} \mathrm{C}$ NMR: DMSO (39.52) at $75 \mathrm{MHz}$. Spectra were taken in DMSO and $\mathrm{CDCl}_{3}$ with shifts reported in parts per million ( $\mathrm{ppm}$ ) referenced to protium or carbon of the solvent $(2.50,7.26$, and 39.52 , respectively). The NMR coupling constants were reported in Hertz (Hz). Highresolution mass spectra (HRMS) were acquired on a Thermo Scientific Exactive Orbitrap mass spectrometer and reported as $m / z$ for the molecular ion $[\mathrm{M}+\mathrm{H}]^{+}$and $[\mathrm{M}]^{+}$.

Syntheses. General Procedure for the Synthesis of Compounds 8-26. To the solution of 7, in $\mathrm{CH}_{2} \mathrm{Cl}_{2}$ (DCM), added corresponding acid chloride at $10-20{ }^{\circ} \mathrm{C}$ and the mixture was stirred at RT for $6 \mathrm{~h}$. Later, excess of DCM was added to the product, washed with saturated $\mathrm{NaHCO}_{3}$ solution, and followed by brine solution. The organic DCM layer was dried with $\mathrm{Na}_{2} \mathrm{SO}_{4}$, filtered, and distilled under reduced pressure. The crude products were purified by column chromatography affording the products, 8-24.

Methyl-6-(2-(adamantane-1-carboxamido) phenyl)-4amino-3-chloropicolinate (8). Compound 7 (38 mg, 0.14 mmol) was initially dissolved in DCM $(2.0 \mathrm{~mL})$ solvent and cooled to $10-20{ }^{\circ} \mathrm{C}$. To this mixture, adamantane-1-carbonyl chloride $(27 \mathrm{mg}, 0.14 \mathrm{mmol})$ was added slowly and stirred for $6 \mathrm{~h}$ at RT. After completion of the reaction, the crude product was diluted with DCM, washed with aqueous sodium bicarbonate, and followed by brine solution, respectively. The DCM layer was dried with sodium sulfate, filtered, and distilled under vacuum. The crude product was purified using column chromatography with EtOAc/Hexane (40:60) to afford compound 8, (51 mg, 85\%). M.P: $285-287{ }^{\circ} \mathrm{C} ;{ }^{1} \mathrm{H}$ NMR (300 MHz, DMSO): $\delta 10.84(\mathrm{~s}, 1 \mathrm{H}), 8.30(\mathrm{~d}, J=8.1$ $\mathrm{Hz}, 1 \mathrm{H}), 7.53(\mathrm{~d}, J=7.6 \mathrm{~Hz}, 1 \mathrm{H}), 7.39(\mathrm{t}, 1 \mathrm{H}), 7.19(\mathrm{t}, 1 \mathrm{H})$, 7.14 (s, 1H), 6.97 (s, 2H), $3.89(\mathrm{~s}, 3 \mathrm{H}), 1.99(\mathrm{~m}, 3 \mathrm{H}), 1.76$ $(\mathrm{m}, 6 \mathrm{H}), 1.68(\mathrm{~d}, 6 \mathrm{H}) ;{ }^{13} \mathrm{C}$ NMR (75 MHz, DMSO): $\delta$ 175.2, 165.2 , 155.0, 152.8, 147.0, 136.6, 129.4, 129.1, 126.7, 123.5, 121.8, 111.0, 109.5, 52.6, 41.0, 38.5, 35.8, 27.5; HRMS $m / z$ : $440.3778[\mathrm{M}+\mathrm{H}]^{+}$calcd for $\mathrm{C}_{24} \mathrm{H}_{26} \mathrm{ClN}_{3} \mathrm{O}_{3}, \mathrm{C}, 65.52 ; \mathrm{H}$, 5.96; N, 9.55; found, C, 65.93; H, 6.19; N, 9.20.

Compounds 9-24 were synthesized similar to the reaction employed for compound 8 . The spectral data for compounds 9-24 are followed (Supporting Information, for the detailed spectral data).

Methyl-6-(2-(1-naphthamido) phenyl)-4-amino-3-chloropyridine-2-carboxylate (9). The compound 9 was purified by column chromatography with EtOAc/Hexane (60:40) as a white solid, 93\% yield; mp $277-279{ }^{\circ} \mathrm{C}$; ${ }^{1} \mathrm{H}$ NMR $(300 \mathrm{MHz}$,
DMSO): $\delta 12.00(\mathrm{~s}, 1 \mathrm{H}), 8.88(\mathrm{~d}, J=4.3 \mathrm{~Hz}, 1 \mathrm{H}), 8.25(\mathrm{~d}, J=$ $8.3 \mathrm{~Hz}, 1 \mathrm{H}), 8.18$ (d, $J=7.7 \mathrm{~Hz}, 2 \mathrm{H}), 7.85(\mathrm{~m}, 2 \mathrm{H}), 7.65$ (d, $J$ $=7.7 \mathrm{~Hz}, 1 \mathrm{H}), 7.51(\mathrm{~m}, 1 \mathrm{H}), 7.32(\mathrm{t}, 3 \mathrm{H}), 7.23(\mathrm{~s}, 1 \mathrm{H}), 6.92$ $(\mathrm{m}, 2 \mathrm{H}), 3.48(\mathrm{~s}, 3 \mathrm{H}) ;{ }^{13} \mathrm{C}$ NMR (75 MHz, DMSO): $\delta 164.8$, $163.4,154.1,152.8,150.2,145.9,142.6,142.1,137.1,136.0$, $132.2,129.8,128.9,127.3,127.2,124.9,123.2,122.5,119.5$, 111.4, 109.3, 52.3; HRMS $m / z: 432.0783\left(\mathrm{M}+\mathrm{H}^{+}\right)$calcd for $\mathrm{C}_{24} \mathrm{H}_{18} \mathrm{ClN}_{3} \mathrm{O}_{3}, \mathrm{C}, 66.75 ; \mathrm{H}, 4.20 ; \mathrm{N}, 9.73$; found, $\mathrm{C}, 67.57 ; \mathrm{H}$, 4.59; N, 9.32.

Methyl-6-(2-(2-phenylacetamido) phenyl)-4-amino-3chloropyridine-2-carboxylate (10). The compound 10 was purified by using column chromatography with EtOAc/ Hexane (25:75) as an off white solid, 95\% yield; mp 296$299{ }^{\circ} \mathrm{C}$; ${ }^{1} \mathrm{H}$ NMR (300 MHz, DMSO): $\delta 11.67(\mathrm{~S}, 1 \mathrm{H}), 8.21$ $(\mathrm{d}, J=8.1 \mathrm{~Hz}, 1 \mathrm{H}), 7.61(\mathrm{~m}, 1 \mathrm{H}), 7.38(\mathrm{~m}, 2 \mathrm{H}), 7.28(\mathrm{~m}$, $4 \mathrm{H}), 7.22(\mathrm{~m}, 4 \mathrm{H}), 3.91(\mathrm{~s}, 3 \mathrm{H}), 3.62(\mathrm{~s}, 2 \mathrm{H}) ;{ }^{13} \mathrm{C}$ NMR $(75$ MHz, DMSO): $\delta$ 168.9, 163.7, 153.9, 152.8, 144.2, 136.7, $135.6,130.1,129.3,129.1,128.3,128.3,128.2,126.5,125.8$, 124.1, 111.9, 109.4, 53.1, 43.6; HRMS $m / z: 396.1109[\mathrm{M}+$ $\mathrm{H}]^{+}$calcd for $\mathrm{C}_{21} \mathrm{H}_{18} \mathrm{ClN}_{3} \mathrm{O}_{3}, \mathrm{C}, 63.72 ; \mathrm{H}, 4.58 ; \mathrm{N}, 10.62$; found, C, 63.18; H, 4.20; N, 11.14.

Methyl-6-(2-(2-(4-fluorophenyl) acetamido) phenyl)-4amino-3-chloropyridine-2-carboxylate (11). The compound 11 was purified by column chromatography with EtOAc/ Hexane (20:80) as an off white solid, 92\% yield; mp 309-312 ${ }^{\circ} \mathrm{C}$; ${ }^{1} \mathrm{H}$ NMR (300 MHz, DMSO): $\delta 11.68(\mathrm{~s}, 1 \mathrm{H}), 8.20$ (d, J $=7.7 \mathrm{~Hz}, 1 \mathrm{H}), 7.61(\mathrm{~m}, 1 \mathrm{H}), 7.41(\mathrm{~m}, 2 \mathrm{H}), 7.30(\mathrm{~m}, 2 \mathrm{H})$, $7.21(\mathrm{~m}, 2 \mathrm{H}), 7.07(\mathrm{~m}, 3 \mathrm{H}), 3.91(\mathrm{~s}, 3 \mathrm{H}), 3.64(\mathrm{~s}, 2 \mathrm{H}) ;{ }^{13} \mathrm{C}$ NMR (75 MHz, DMSO): $\delta$ 168.5, 166.3, 163.4, 152.8, 144.6, 136.2 , 135.9, 130.4, 129.6, 128.9, 128.6, 126.8, 125.7, 116.9, 116.6, 111.7, 109.3, 53.5, 44.2; HRMS $m / z: 414.0863[\mathrm{M}+$ $\mathrm{H}]^{+}$calcd for $\mathrm{C}_{21} \mathrm{H}_{17} \mathrm{ClFN}_{3} \mathrm{O}_{3}, \mathrm{C}, 60.95 ; \mathrm{H}, 4.14 ; \mathrm{N}, 10.15$; found, $\mathrm{C}, 60.31 ; \mathrm{H}, 3.89 ; \mathrm{N}, 11.00$.

Methyl-6-(2-(2-(4-chlorophenyl) acetamido) phenyl)-4amino-3-chloropyridine-2-carboxylate (12). The compound 12 was purified using column chromatography with EtOAc/ Hexane (16:84) as a white solid, $91 \%$ yield; mp $302-305{ }^{\circ} \mathrm{C}$; ${ }^{1} \mathrm{H}$ NMR (300 MHz, DMSO): $\delta 11.9(\mathrm{~s}, 1 \mathrm{H}), 9.05$ (s, 1H), $8.51(\mathrm{~d}, J=8.4 \mathrm{~Hz}, 1 \mathrm{H}), 8.11(\mathrm{~s}, 1 \mathrm{H}), 7.70(\mathrm{~d}, J=7.5 \mathrm{~Hz}$, $1 \mathrm{H}), 7.42(\mathrm{~m}, 3 \mathrm{H}), 7.32(\mathrm{~m}, 3 \mathrm{H}), 7.16(\mathrm{t}, 1 \mathrm{H}), 4.00(\mathrm{~s}, 3 \mathrm{H})$, $3.86(\mathrm{~s}, 2 \mathrm{H}) ;{ }^{13} \mathrm{C}$ NMR (75 MHz, DMSO): $\delta$ 168.7, 164.6, $155.2,154.8,151.1,147.5,144.2,131.3,130.9,128.2,128.2$, 128.1, 118.0, 111.2, 109.4, 109.0, 53.0, 42.1; HRMS $m / z$ : 430.0720 $[\mathrm{M}+\mathrm{H}]^{+}$calcd for $\mathrm{C}_{21} \mathrm{H}_{17} \mathrm{Cl}_{3} \mathrm{~N}_{3} \mathrm{O}_{3}, \mathrm{C}, 54.16 ; \mathrm{H}$, 3.68; N, 9.02; found, C, 54.79; H, 3.94; N, 8.57.

Methyl-6-(2-(2-phenoxyacetamido) phenyl)-4-amino-3chloropyridine-2-carboxylate (13). The compound 13 was purified using column chromatography with EtOAc/Hexane (30:70) as an off white solid, $84 \%$ yield; mp $275-278{ }^{\circ} \mathrm{C} ;{ }^{1} \mathrm{H}$ NMR (300 MHz, DMSO): $\delta 11.29$ (s, 1H), 8.22 (d, $J=8.3$ $\mathrm{Hz}, 1 \mathrm{H}), 7.55$ (d, J = 7.7 Hz, 2H), $7.45(\mathrm{~m}, 2 \mathrm{H}), 7.29(\mathrm{~m}$, 5H), 7.09 (m, 2H), 4.66 (s, 2H), 3.77 (s, 3H); ${ }^{13} \mathrm{C}$ NMR (75 MHz, DMSO): $\delta 166.7,164.5,157.4,153.8,153.2,135.5$, $129.7,129.1,127.2,124.3,122.3,121.4,121.2,120.9,114.8$, 111.6, 109.4, 67.7, 52.6; HRMS $m / z: 412.1058[\mathrm{M}+\mathrm{H}]^{+}$, calcd for $\mathrm{C}_{21} \mathrm{H}_{18} \mathrm{ClN}_{3} \mathrm{O}_{4}, \mathrm{C}, 61.24 ; \mathrm{H}, 4.41 ; \mathrm{N}, 10.20$; found, C, 60.75; H, 4.15; N, 10.68 .

Methyl-4-amino-3-chloro-6-(2-(furan-2-carboxamido) phenyl) pyridine-2-carboxylate (14). The compound 14 was purified by column chromatography with EtOAc/Hexane $(25: 75)$ as a white solid, $87 \%$ yield; mp $293-295{ }^{\circ} \mathrm{C} ;{ }^{1} \mathrm{H}$ NMR (400 MHz, DMSO): $\delta 12.24(\mathrm{~s}, 1 \mathrm{H}), 8.43(\mathrm{~m}, 1 \mathrm{H})$, $7.77(\mathrm{~m}, 1 \mathrm{H}), 7.64(\mathrm{~m}, 1 \mathrm{H}), 7.47(\mathrm{~m}, 1 \mathrm{H}), 7.27(\mathrm{~m}, 1 \mathrm{H}), 7.25$ 
(m, 1H), $7.20(\mathrm{~m}, 1 \mathrm{H}), 7.19(\mathrm{~s}, 2 \mathrm{H}), 6.72(\mathrm{~m}, 1 \mathrm{H}), 3.94(\mathrm{~s}$, $3 \mathrm{H}) ;{ }^{13} \mathrm{C}$ NMR (75 MHz, DMSO): $\delta$ 165.4, 156.7, 155.8, $151.8,148.4,146.7,144.7,136.5,130.2,129.0,126.4,124.1$, 122.4, 114.9, 113.4, 112.3, 109.9, 53.0; HRMS $m / z: 372.0747$ $[\mathrm{M}+\mathrm{H}]^{+}$calcd for $\mathrm{C}_{18} \mathrm{H}_{14} \mathrm{ClN}_{3} \mathrm{O}_{4}, \mathrm{C}, 58.15 ; \mathrm{H}, 3.80 ; \mathrm{N}$, 11.30; found, C, 58.71; H, 4.19; N, 10.95 .

Methyl-6-(2-(3-(trifluoromethyl) pyridine-2-carboxamido) phenyl)-4-amino-3-chloropyridine-2-carboxylate (15). The compound 15 was purified by column chromatography with EtOAc/Hexane (40:60) as a white solid, 76\% yield; mp 284$286{ }^{\circ} \mathrm{C}$; ${ }^{1} \mathrm{H}$ NMR (300 MHz, DMSO): $\delta 12.76(\mathrm{~s}, 1 \mathrm{H}), 8.82$ $(\mathrm{d}, J=4.1 \mathrm{~Hz}, 1 \mathrm{H}), 8.51(\mathrm{~d}, J=8.3 \mathrm{~Hz}, 1 \mathrm{H}), 8.42(\mathrm{~d}, J=7.7$ $\mathrm{Hz}, 1 \mathrm{H}), 7.87(\mathrm{dd}, 1 \mathrm{H}), 7.66(\mathrm{~d}, J=7.7 \mathrm{~Hz}, 1 \mathrm{H}), 7.51(\mathrm{t}, 1 \mathrm{H})$, $7.30(\mathrm{t}, 1 \mathrm{H}), 7.22(\mathrm{~s}, 1 \mathrm{H}), 6.96(\mathrm{~s}, 2 \mathrm{H}), 3.71(\mathrm{~s}, 3 \mathrm{H}) ;{ }^{13} \mathrm{C}$ NMR (75 MHz, DMSO): $\delta$ 165.0, 161.8, 154.3, 153.0, 151.7, $149.7,146.7,136.1,129.8,129.0,126.4,126.0,124.4,121.2$, 111.2, 109.3, 52.5; HRMS $m / z: 451.0783[\mathrm{M}+\mathrm{H}]^{+}$calcd for $\mathrm{C}_{20} \mathrm{H}_{14} \mathrm{ClF}_{3} \mathrm{~N}_{4} \mathrm{O}_{3}, \mathrm{C}, 61.00 ; \mathrm{H}, 3.58 ; \mathrm{N}, 14.23$, found, C, 61.54; $\mathrm{H}, 3.86$; N, 13.74 .

Methyl-6-(2-(2,6-dichlorobenzamido)phenyl)-4-amino-3chloropyridine-2-carboxylate (16). The compound 16 was purified by column chromatography with EtOAc/Hexane $(45: 55)$ as an off white solid, $82 \%$ yield; mp $254-257{ }^{\circ} \mathrm{C}$; ${ }^{1} \mathrm{H}$ NMR (300 MHz, DMSO): $\delta 12.04$ (s, 1H), 8.29 (d, $J=8.3$ $\mathrm{Hz}, 1 \mathrm{H}), 7.65(\mathrm{~m}, 1 \mathrm{H}), 7.57(\mathrm{~m}, 2 \mathrm{H}), 7.51(\mathrm{~m}, 2 \mathrm{H}), 7.32(\mathrm{t}$, $1 \mathrm{H}), 7.22$ (s, 1H), 6.94 (s, 2H), $3.48(\mathrm{~s}, 3 \mathrm{H}) ;{ }^{13} \mathrm{C}$ NMR (75 $\mathrm{MHz}, \mathrm{DMSO}): \delta 161.9,153.4,153.1,136.0,135.8,131.4$, $131.0,129.9,128.9,128.3,128.2,126.8,124.9,122.7,111.7$, 109.5, 52.5; HRMS $m / z$ : 450.0176 $[\mathrm{M}+\mathrm{H}]^{+}$calcd for $\mathrm{C}_{20} \mathrm{H}_{14} \mathrm{Cl}_{3} \mathrm{~N}_{3} \mathrm{O}_{3}, \mathrm{C}, 53.30 ; \mathrm{H}, 3.13 ; \mathrm{N}, 9.32$; found, C, 53.98; $\mathrm{H}, 3.39$; N, 8.84.

Methyl-6-(2-(2-(trifluoromethyl) benzamido) phenyl)-4amino-3-chloropyridine-2-carboxylate (17). The compound 17 was purified by column chromatography with EtOAc/ Hexane (20:80) as an off white solid, 90\% yield; mp 234-237 ${ }^{\circ} \mathrm{C}$; ${ }^{1} \mathrm{H}$ NMR (300 MHz, DMSO): $\delta 11.93(\mathrm{~s}, 1 \mathrm{H}), 8.30$ (d, $J$ $=8.3 \mathrm{~Hz}, 1 \mathrm{H}), 7.85(\mathrm{~d}, J=7.7 \mathrm{~Hz}, 1 \mathrm{H}), 7.76(\mathrm{~m}, 2 \mathrm{H}), 7.66$ $(\mathrm{m}, 2 \mathrm{H}), 7.50(\mathrm{~m}, 1 \mathrm{H}), 7.30(\mathrm{t}, 1 \mathrm{H}), 7.24(\mathrm{~s}, 1 \mathrm{H}), 6.96(\mathrm{~s}$, $2 \mathrm{H}), 3.45$ (s, 3H); ${ }^{13} \mathrm{C}$ NMR (75 MHz, DMSO): $\delta 165.2$, $164.3,153.9,145.5,136.4,136.1,132.7,130.2,129.9,129.0$, $128.2,126.6,126.3,125.6,124.6,122.4,121.9,111.5,109.3$, 52.4; HRMS $m / z: 450.0826[\mathrm{M}+\mathrm{H}]^{+}$calcd for $\mathrm{C}_{21} \mathrm{H}_{15} \mathrm{~F}_{3} \mathrm{~N}_{3} \mathrm{O}_{3}, \mathrm{C}, 60.87$; $\mathrm{H}, 3.65$; N, 10.14; found, C, 60.18; $\mathrm{H}, 3.27$; N, 10.74 .

Methyl-6-(2-(2,6-difluoro-4-methoxybenzamido)phenyl)4-amino-3-chloropyridine-2-carboxylate (18). The compound 18 was purified by column chromatography with EtOAc/Hexane (20:80) as an off white solid, 93\% yield; mp 211-214 ${ }^{\circ} \mathrm{C}$; ${ }^{1} \mathrm{H}$ NMR (300 MHz, DMSO): $\delta 12.16(\mathrm{~S}, 1 \mathrm{H})$, $8.40(\mathrm{~d}, J=8.3 \mathrm{~Hz}, 1 \mathrm{H}), 7.66(\mathrm{~d}, J=7.7 \mathrm{~Hz}, 1 \mathrm{H}), 7.49(\mathrm{t}, 1 \mathrm{H})$, $7.29(\mathrm{t}, 1 \mathrm{H}), 7.24(\mathrm{~s}, 1 \mathrm{H}), 6.98(\mathrm{~s}, 2 \mathrm{H}), 6.87(\mathrm{~d}, J=10.2 \mathrm{~Hz}$, $2 \mathrm{H}), 3.85(\mathrm{~s}, 3 \mathrm{H}), 3.60(\mathrm{~s}, 3 \mathrm{H}) ;{ }^{13} \mathrm{C}$ NMR (75 MHz, DMSO): $\delta 164.2,162.0,161.7,161.6,158.4,157.8,153.6,145.2,136.3$, 130.0, 128.9, 125.8, 124.6, 121.9, 111.6, 109.3, 98.9, 98.5, 56.3, 52.6; HRMS $m / z$ 448.0869 $[\mathrm{M}+\mathrm{H}]^{+}$calcd for $\mathrm{C}_{21} \mathrm{H}_{16} \mathrm{ClF}_{2} \mathrm{~N}_{3} \mathrm{O}_{4}, \mathrm{C}, 56.32 ; \mathrm{H}, 3.60 ; \mathrm{N}, 9.38$; found, $\mathrm{C}$, 57.05; H, 3.92; N, 8.90.

Methyl-6-(2-(4-(trifluoromethyl) benzamido) phenyl)-4amino-3-chloropyridine-2-carboxylate (19). The compound 19 was purified by column chromatography with EtOAc/ Hexane (40:60) as an off white solid, 85\% yield; mp 204-207 ${ }^{\circ} \mathrm{C}$; ${ }^{1} \mathrm{H}$ NMR (300 MHz, DMSO): $\delta 12.15$ (s, 1H), 8.62 (d, J $=5.1 \mathrm{~Hz}, 1 \mathrm{H}), 8.08(\mathrm{~d}, J=5.1 \mathrm{~Hz}, 2 \mathrm{H}), 7.74(\mathrm{~d}, J=4.5 \mathrm{~Hz}$,
$2 \mathrm{H}), 7.52(\mathrm{~m}, 1 \mathrm{H}), 7.47(\mathrm{t}, 1 \mathrm{H}), 7.19(\mathrm{t}, 1 \mathrm{H}), 7.09(\mathrm{~s}, 1 \mathrm{H})$, $5.01(\mathrm{~s}, 2 \mathrm{H}), 3.87(\mathrm{~s}, 3 \mathrm{H}) ;{ }^{13} \mathrm{C} \mathrm{NMR}(75 \mathrm{MHz}, \mathrm{DMSO}): \delta$ $165.0,163.6,154.5,153.0,146.6,138.6,136.3,129.8,129.1$, 128.1, 126.9, 125.5, 124.5, 122.3, 111.2, 109.4, 52.5; HRMS $m / z: 450.0823[\mathrm{M}+\mathrm{H}]^{+}$calcd for $\mathrm{C}_{21} \mathrm{H}_{15} \mathrm{ClF}_{3} \mathrm{~N}_{3} \mathrm{O}_{3}, \mathrm{C}, 57.71$; $\mathrm{H}, 3.63$; N, 10.09; found, C, 57.29; H, 3.49; N, 10.48 .

Methyl-6-(2-(2,4-difluorobenzamido)phenyl)-4-amino-3chloropyridine-2-carboxylate (20). The compound 20 was purified using column chromatography with EtOAc/Hexane (45:55) as a white solid, $89 \%$ yield; mp $227-229{ }^{\circ} \mathrm{C}$; ${ }^{1} \mathrm{H}$ NMR (300 MHz, DMSO): $\delta 11.694(\mathrm{~s}, 1 \mathrm{H}), 8.37(\mathrm{~d}, J=8.3 \mathrm{~Hz}$, $1 \mathrm{H}), 7.86(\mathrm{dd}, 1 \mathrm{H}), 7.63(\mathrm{~d}, J=7.9 \mathrm{~Hz}, 1 \mathrm{H}), 7.48(\mathrm{~m}, 1 \mathrm{H})$, $7.43(\mathrm{~m}, 1 \mathrm{H}), 7.29(\mathrm{~m}, 1 \mathrm{H}), 7.23(\mathrm{~m}, 2 \mathrm{H}), 6.95(\mathrm{~s}, 2 \mathrm{H}), 3.75$ $(\mathrm{s}, 3 \mathrm{H}) ;{ }^{13} \mathrm{C}$ NMR (75 MHz, DMSO): $\delta$ 165.5, 164.8, 161.5, $161.3,154.2,153.0,146.4,136.2,132.5,129.7,126.6,124.5$, $122.4,112.4,111.2,109.2$, 105.1, 104.4, 52.6; HRMS $\mathrm{m} / z$ : 418.0769 $[\mathrm{M}+\mathrm{H}]^{+}$calcd for $\mathrm{C}_{20} \mathrm{H}_{14} \mathrm{ClF}_{2} \mathrm{~N}_{3} \mathrm{O}_{3}, \mathrm{C}, 57.50 ; \mathrm{H}$, 3.38; N, 10.06; found, C, 58.24; H, 3.67; N, 9.64.

Methyl-6-(2-(2-chlorobenzamido) phenyl)-4-amino-3chloropyridine-2-carboxylate (21). The compound 21 was purified using column chromatography with EtOAc/Hexane (40:60) as a white solid, $95 \%$ yield; mp $185-187{ }^{\circ} \mathrm{C}$; ${ }^{1} \mathrm{H}$ NMR (300 MHz, DMSO): $\delta 12.07$ (s, $1 \mathrm{H}), 8.68(\mathrm{~d}, J=8.4 \mathrm{~Hz}, 1 \mathrm{H})$, $7.57(\mathrm{~m}, 2 \mathrm{H}), 7.46(\mathrm{~m}, 2 \mathrm{H}), 7.38(\mathrm{~m}, 1 \mathrm{H}), 7.34(\mathrm{t}, 1 \mathrm{H}), 7.20$ $(\mathrm{m}, 1 \mathrm{H}), 7.12(\mathrm{~s}, 1 \mathrm{H}), 4.96(\mathrm{~s}, 2 \mathrm{H}), 3.51(\mathrm{~s}, 3 \mathrm{H}) ;{ }^{13} \mathrm{C} \mathrm{NMR}$ (75 MHz, DMSO): $\delta$ 164.4, 154.1, 153.0, 145.7, 136.4, 131.5, $129.9,129.8,129.0,128.9,127.3,126.5,124.5,122.2,111.5$, 109.3, 52.4; HRMS $m / z$ : 416.05687 $[\mathrm{M}+\mathrm{H}]^{+}$calcd for $\mathrm{C}_{20} \mathrm{H}_{15} \mathrm{Cl}_{2} \mathrm{~N}_{3} \mathrm{O}_{3}, \mathrm{C}, 57.71 ; \mathrm{H}, 3.63 ; \mathrm{N}, 10.09$; found, C, 58.14; $\mathrm{H}, 3.68 ; \mathrm{N}, 9.94$.

Methyl-6-(2-(3-fluorobenzamido) phenyl)-4-amino-3chloropyridine-2-carboxylate (22). The compound 22 was purified using column chromatography with EtOAc/Hexane (25:75) as a white solid, $90 \%$ yield; mp $197-200{ }^{\circ} \mathrm{C} ;{ }^{1} \mathrm{H}$ NMR (300 MHz, DMSO): $\delta 11.9$ (s, $1 \mathrm{H}), 8.37(\mathrm{~d}, J=8.3 \mathrm{~Hz}, 1 \mathrm{H})$, $7.65(\mathrm{t}, 2 \mathrm{H}), 7.58(\mathrm{~m}, 2 \mathrm{H}), 7.48(\mathrm{~m}, 2 \mathrm{H}), 7.29(\mathrm{t}, 1 \mathrm{H}), 7.23$ $(\mathrm{s}, 1 \mathrm{H}), 6.98(\mathrm{~s}, 2 \mathrm{H}), 3.81(\mathrm{~s}, 3 \mathrm{H}) ;{ }^{13} \mathrm{C} \mathrm{NMR}(75 \mathrm{MHz}$, DMSO): $\delta 165.0,163.5,160.5,154.6,153.1,146.6,136.4$, $130.7,129.1,127.0,124.4,123.0,122.4,118.6,114.0,111.3$, 109.5, 52.6; HRMS $m / z$ : $400.0862[\mathrm{M}+\mathrm{H}]^{+}$calcd for $\mathrm{C}_{20} \mathrm{H}_{15} \mathrm{ClFN}_{3} \mathrm{O}_{3}, \mathrm{C}, 60.08 ; \mathrm{H}, 3.78 ; \mathrm{N}, 10.51$; found, C, 60.85; $\mathrm{H}, 4.09$; N, 9.74.

Methyl-6-(2-(2-methoxybenzamido) phenyl)-4-amino-3chloropyridine-2-carboxylate (23). The compound 23 was purified using column chromatography with EtOAc/Hexane (50:50) as an off white solid, 94\% yield; mp $241-244{ }^{\circ} \mathrm{C} ;{ }^{1} \mathrm{H}$ NMR (300 MHz, DMSO): $\delta 11.24(\mathrm{~s}, 1 \mathrm{H}), 8.47$ (d, $J=6.3$ $\mathrm{Hz}, 1 \mathrm{H}), 7.72(\mathrm{~m}, 1 \mathrm{H}), 7.50(\mathrm{~m}, 2 \mathrm{H}), 7.45(\mathrm{~m}, 1 \mathrm{H}), 7.22(\mathrm{t}$, $1 \mathrm{H}), 7.14(\mathrm{~m}, 2 \mathrm{H}), 7.06(\mathrm{t}, 1 \mathrm{H}), 6.91(\mathrm{~s}, 2 \mathrm{H}), 3.59(\mathrm{~m}, 6 \mathrm{H})$; ${ }^{13} \mathrm{C}$ NMR (75 MHz, DMSO): $\delta$ 165.1, 163.7, 156.4, 154.7, $152.7,147.1,136.4,132.6,130.4,129.5,129.2,127.5,123.8$, 121.7, 120.6, 111.9, 111.1, 109.8, 55.3, 52.4; HRMS $m / z$ : 412.1056 $[\mathrm{M}+\mathrm{H}]^{+}$calcd for $\mathrm{C}_{21} \mathrm{H}_{18} \mathrm{ClN}_{3} \mathrm{O}_{4}, \mathrm{C}, 61.24 ; \mathrm{H}$, 4.41; N, 10.20; found, C, 61.73; H, 4.60; N, 9.88.

Methyl-6-(2-(2,6-difluorobenzamido)phenyl)-4-amino-3chloropyridine-2-carboxylate (24). The compound 24 was purified using column chromatography with EtOAc/Hexane (30:70) as an off white solid, 95\% yield; mp $204-206{ }^{\circ} \mathrm{C} ;{ }^{1} \mathrm{H}$ NMR (300 MHz, DMSO): $\delta 12.27(\mathrm{~s}, 1 \mathrm{H}), 8.39$ (d, $J=8.1$ $\mathrm{Hz}, 1 \mathrm{H}), 7.63(\mathrm{~m}, 2 \mathrm{H}), 7.52(\mathrm{t}, 1 \mathrm{H}), 7.29(\mathrm{~m}, 4 \mathrm{H}), 7.02(\mathrm{~s}$, $2 \mathrm{H}), 3.54(\mathrm{~s}, 3 \mathrm{H}) ;{ }^{13} \mathrm{C}$ NMR $(75 \mathrm{MHz}, \mathrm{DMSO}): \delta 163.7$, $161.8,159.8,158.9,154.9,152.0,136.6,131.7,130.4,128.7$, $125.8,124.7,123.1,114.6,112.4,111.9,109.7,52.6$; HRMS 
$m / z: 418.0763[\mathrm{M}+\mathrm{H}]^{+}$calcd for $\mathrm{C}_{20} \mathrm{H}_{14} \mathrm{ClF}_{2} \mathrm{~N}_{3} \mathrm{O}_{3}, \mathrm{C}, 57.50$; $\mathrm{H}, 3.38 ; \mathrm{N}, 10.06$; found, $\mathrm{C}, 56.89 ; \mathrm{H}, 3.11 ; \mathrm{N}, 10.57$.

Methyl-4-amino-3-chloro-6-(2-((4-methoxyphenyl) sulfonamido) phenyl) picolinate (25). The compound 7 (25 mg, $0.090 \mathrm{mmol})$ was dissolved initially in DCM $(2.5 \mathrm{~mL})$ solvent and DIPEA (19 $\mu \mathrm{L}, 0.11 \mathrm{mmol})$. Later to this reaction mixture, 4-methoxy benzenesulfonylchloride (19 $\mathrm{mg}, 0.090 \mathrm{mmol}$ ) was added and the whole reaction mixture was stirred for $4 \mathrm{~h}$ at RT. After completion of the reaction, the crude product was diluted with DCM and washed with saturated sodium bicarbonate solution and brine solution, respectively. The DCM layer was dried with sodium sulfate and filtered, and solvent was removed under vacuum. The crude product was purified using column chromatography with EtOAc/Hexane (30:70) as a white solid, $72 \%$ yield; $\mathrm{mp} 284-287{ }^{\circ} \mathrm{C} ;{ }^{1} \mathrm{H}$ NMR (300 MHz, DMSO): $\delta 11.34(\mathrm{~s}, 1 \mathrm{H}), 7.71(\mathrm{~m}, 1 \mathrm{H}), 7.47(\mathrm{~m}$, $4 \mathrm{H}), 7.32(\mathrm{~m}, 1 \mathrm{H}), 7.14(\mathrm{~m}, 1 \mathrm{H}), 6.97(\mathrm{~m}, 2 \mathrm{H}), 6.83(\mathrm{~m}, 1 \mathrm{H})$, $6.71(\mathrm{~d}, J=8.7 \mathrm{~Hz}, 1 \mathrm{H}), 4.08(\mathrm{~s}, 3 \mathrm{H}), 3.78(\mathrm{~s}, 3 \mathrm{H}) ;{ }^{13} \mathrm{C} \mathrm{NMR}$ (75 MHz, DMSO): $\delta$ 167.3, 164.8, 163.3, 155.2, 151.3, 143.5, $137.1,134.6,130.0,129.3,128.6,126.3,125.4,124.0,116.1$, 114.4, 107.1, 56.4, 53.6; HRMS $m / z: 448.0729[\mathrm{M}+\mathrm{H}]^{+}$ calcd for $\mathrm{C}_{20} \mathrm{H}_{18} \mathrm{ClN}_{3} \mathrm{O}_{5} \mathrm{~S}, \mathrm{C}, 53.63 ; \mathrm{H}, 4.05 ; \mathrm{N}, 9.38 ; \mathrm{S}, 7.16$, found, C, 53.25; H, 3.79; N, 9.94; S, 7.25.

Methyl-4-amino-3-chloro-6-(2-((4-fluorophenyl) sulfonamido) phenyl) picolinate (26). The compound 7 (30 mg, 0.11 mmol) was dissolved in DCM (3 mL) solvent, and DIPEA (23 $\mu \mathrm{L}, 0.13 \mathrm{mmol}$ ) and 4-fluoro benzenesulfonylchloride $(21 \mathrm{mg}$, $0.11 \mathrm{mmol}$ ) were added simultaneously and stirred for $4 \mathrm{~h}$ at RT. After completion of the reaction, the product was diluted with DCM, washed with saturated sodium bicarbonate solution, and followed by brine solution, respectively. Later, the DCM layer was dried with sodium sulfate and filtered, and solvent was removed under vacuum. The crude product was purified using column chromatography with mixed solvent of EtOAc/Hexane (20:80) as a white solid, 79\% yield; mp 269$272{ }^{\circ} \mathrm{C}$; ${ }^{1} \mathrm{H}$ NMR (300 MHz, DMSO): $\delta 12.06$ (s, 1H), 7.70 $(\mathrm{d}, J=8.1 \mathrm{~Hz}, 1 \mathrm{H}), 7.56(\mathrm{~m}, 2 \mathrm{H}), 7.46(\mathrm{~d}, J=7.5 \mathrm{~Hz}, 1 \mathrm{H})$, $7.35(\mathrm{t}, 1 \mathrm{H}), 7.13(\mathrm{t}, 1 \mathrm{H}), 6.89(\mathrm{t}, 2 \mathrm{H}), 6.82(\mathrm{~s}, 1 \mathrm{H}), 4.99(\mathrm{~s}$, $2 \mathrm{H}), 4.08(\mathrm{~s}, 3 \mathrm{H}) ;{ }^{13} \mathrm{C}$ NMR (75 MHz, DMSO): $\delta 166.7$, $164.3,154.1,151.8,144.0,136.9,135.5,130.6,129.7,129.5$, $128.2,126.0,124.9,123.7,116.0,115.7,108.5,53.2$; HRMS $m / z: 436.0531[\mathrm{M}+\mathrm{H}]^{+}$calcd for $\mathrm{C}_{19} \mathrm{H}_{15} \mathrm{ClFN}_{3} \mathrm{O}_{4} \mathrm{~S}, \mathrm{C}, 52.36$; H, 3.47; N, 9.64; S, 7.36; found, C, 52.96; H, 3.68; N, 9.01; S, 7.04 .

General Procedure for the Synthesis of Compounds, 2737. To the solution of compound 7 in DCM, added trimethylamine (TEA). To this reaction mixture, corresponding isocyanate and isothiocyanate reactants were added simultaneously under a nitrogen atmosphere. The whole reaction mixture was stirred at RT for $4 \mathrm{~h}$. The product was extracted with DCM, washed with water, and followed by brine solution, respectively. Later, the DCM layer was dried with $\mathrm{Na}_{2} \mathrm{SO}_{4}$ and distilled under reduced pressure to remove the solvent. The crude product was purified by column chromatography to afford the products, 27-37.

Methyl-4-amino-3-chloro-6-(2-(3-(4-chlorophenyl) thioureido) phenyl) pyridine-2-carboxylate (27). The compound $7(20 \mathrm{mg}, 0.072 \mathrm{mmol})$ was dissolved in DCM $(2.0 \mathrm{~mL})$, and TEA $(11 \mu \mathrm{L}, 0.079 \mathrm{mmol})$ was added to the mixture under a $\mathrm{N}_{2}$ atmosphere. Later, 1-chloro-4-isothio cyanatobenzene (12 $\mathrm{mg}, 0.073 \mathrm{mmol}$ ) was added and the reaction mixture was stirred for $4 \mathrm{~h}$ at RT. After completion of the reaction, the product was diluted with DCM and washed with water and brine solution. The DCM layer was dried with sodium sulfate, filtered, and distilled out under vacuum. The compound 27 was purified using column chromatography with EtOAc/ Hexane (35:65) to get the compound $27(26 \mathrm{mg}, 82 \%)$ as a white solid. mp $217-219{ }^{\circ} \mathrm{C} ;{ }^{1} \mathrm{H}$ NMR (300 MHz, DMSO): $\delta$ $10.8(\mathrm{~s}, 1 \mathrm{H}), 9.1(\mathrm{~s}, 1 \mathrm{H}), 8.29(\mathrm{~d}, J=8.3 \mathrm{~Hz}, 1 \mathrm{H}), 7.65(\mathrm{~m}$, $1 \mathrm{H}), 7.57(\mathrm{~m}, 2 \mathrm{H}), 7.51(\mathrm{~m}, 2 \mathrm{H}), 7.32(\mathrm{t}, 2 \mathrm{H}), 7.22(\mathrm{~s}, 1 \mathrm{H})$, $6.94(\mathrm{~s}, 2 \mathrm{H}), 3.48(\mathrm{~s}, 3 \mathrm{H}) ;{ }^{13} \mathrm{C}$ NMR (75 MHz, DMSO): $\delta$ $179.5,169.9,154.4,152.2,147.4,138.2,137.0,131.3,129.1$, $128.6,128.3,128.1,127.0,126.9,125.2,110.8,109.5,52.5$; HRMS $m / z 447.0441[\mathrm{M}+\mathrm{H}]^{+}$calcd for $\mathrm{C}_{20} \mathrm{H}_{16} \mathrm{Cl}_{2} \mathrm{~N}_{4} \mathrm{O}_{2} \mathrm{~S}, \mathrm{C}$, 53.70; H, 3.61; N, 12.52; S, 7.17; found, C, 54.26; H, 3.89; N, 12.04; S, 6.89 .

Compounds 28-37 were synthesized similar to the reactions employed for the compound 27 . The spectral data for compounds 28-37 are followed (Supporting Information for the detailed spectral data and other information).

Methyl-4-amino-3-chloro-6-(2-(3-(2-chlorophenyl) thioureido) phenyl) pyridine-2-carboxylate (28). The compound 28 was purified using column chromatography with EtOAc/ Hexane (40:60) as an off white solid, 89\% yield; mp 230-232 ${ }^{\circ} \mathrm{C}$; ${ }^{1} \mathrm{H}$ NMR (300 MHz, DMSO): $\delta 10.7$ (s, 1H), 9.06 (s, $1 \mathrm{H}), 8.30(\mathrm{~d}, J=8.3 \mathrm{~Hz}, 1 \mathrm{H}), 7.85(\mathrm{~m}, 1 \mathrm{H}), 7.76(\mathrm{~m}, 2 \mathrm{H})$, $7.66(\mathrm{~m}, 2 \mathrm{H}), 7.50(\mathrm{~m}, 1 \mathrm{H}), 7.30(\mathrm{t}, 1 \mathrm{H}), 7.24(\mathrm{~s}, 1 \mathrm{H}), 6.96$ (s, 2H), 3.45 (s, 3H); ${ }^{13} \mathrm{C}$ NMR (75 MHz, DMSO): $\delta$ 180.2, $167.1,154.2$, 152.2, 147.3, 138.0, 137.4, 131.1, 129.4, 128.9, $128.7,128.3,127.5,126.8,125.2,124.7,110.9,109.0,53.2$; HRMS $m / z: 447.0695[\mathrm{M}+\mathrm{H}]^{+}$calcd for $\mathrm{C}_{20} \mathrm{H}_{16} \mathrm{C}_{12} \mathrm{~N}_{4} \mathrm{O}_{2} \mathrm{~S}$, C, 53.70; H, 3.61; N, 12.52; S, 7.17; found, C, 54.09; H, 3.91; $\mathrm{N}, 12.20 ; \mathrm{S}, 6.97$.

Methyl-4-amino-3-chloro-6-(2-(3-(3-chlorophenyl) thioureido) phenyl) pyridine-2-carboxylate (29). The compound 29 was purified using column chromatography with EtOAc/ Hexane (30:70) as an off white solid, 96\% yield; mp 216-218 ${ }^{\circ} \mathrm{C}$; ${ }^{1} \mathrm{H}$ NMR (300 MHz, DMSO): $\delta 11.1(\mathrm{~s}, 1 \mathrm{H}), 9.21(\mathrm{~s}$, $1 \mathrm{H}), 8.36(\mathrm{~d}, J=8.4 \mathrm{~Hz}, 1 \mathrm{H}), 7.57(\mathrm{~m}, 2 \mathrm{H}), 7.46(\mathrm{~m}, 2 \mathrm{H})$, $7.38(\mathrm{~m}, 1 \mathrm{H}), 7.34(\mathrm{t}, 1 \mathrm{H}), 7.20(\mathrm{~m}, 1 \mathrm{H}), 7.12(\mathrm{~s}, 1 \mathrm{H}), 6.86$ $(\mathrm{s}, 2 \mathrm{H}), 3.51(\mathrm{~s}, 3 \mathrm{H}) ;{ }^{13} \mathrm{C}$ NMR (75 MHz, DMSO): $\delta 180.5$, $168.1,154.2,152.2,147.4,136.9,136.4,129.9,129.4,128.2$, $127.7,123.8,123.4,122.9,122.8,111.4,110.4,52.1$; HRMS $m / z: 447.0698[\mathrm{M}+\mathrm{H}]^{+}$calcd for $\mathrm{C}_{20} \mathrm{H}_{16} \mathrm{C}_{12} \mathrm{~N}_{4} \mathrm{O}_{2} \mathrm{~S}, \mathrm{C}, 53.70$; $\mathrm{H}, 3.61$; N, 12.52; S, 7.17; found, C, 53.14; H, 3.28; N, 12.95; S, 7.74 .

9-Methyl-amino-6-(2-(3-(2-bromophenyl) thioureido) phenyl)-3-chloropyridine-2-carboxylate (30). The compound 30 was purified using column chromatography with EtOAc/ Hexane (25:75) as a white solid, $90 \%$ yield; mp $236-238{ }^{\circ} \mathrm{C}$; ${ }^{1} \mathrm{H}$ NMR (300 MHz, DMSO): $\delta 10.8(\mathrm{~s}, 1 \mathrm{H}), 9.1(\mathrm{~s}, 1 \mathrm{H})$, $8.37(\mathrm{~d}, J=8.3 \mathrm{~Hz}, 1 \mathrm{H}), 7.65(\mathrm{t}, 2 \mathrm{H}), 7.58(\mathrm{~m}, 2 \mathrm{H}), 7.48(\mathrm{~m}$, $2 \mathrm{H}), 7.29(\mathrm{t}, 1 \mathrm{H}), 7.23(\mathrm{~s}, 1 \mathrm{H}), 6.98(\mathrm{~s}, 2 \mathrm{H}), 3.81(\mathrm{~s}, 3 \mathrm{H}) ;{ }^{13} \mathrm{C}$ NMR (75 MHz, DMSO): $\delta 179.7,165.5,154.0,152.0,146.8$, 137.3 , 132.4, 129.8, 128.3, 125.7, 123.6, 121.6, 121.2, 120.0, $119.9,111.7,109.8,52.5$; HRMS $m / z: 490.2897[\mathrm{M}]^{+}$calcd for $\mathrm{C}_{20} \mathrm{H}_{16} \mathrm{BrClN}_{4} \mathrm{O}_{2} \mathrm{~S}, \mathrm{C}, 48.85 ; \mathrm{H}, 3.28 ; \mathrm{N}, 11.39 ; \mathrm{S}, 6.52$; found, C, 49.07; H, 3.52; N, 11.06; S, 6.24.

Methyl-4-amino-6-(2-(3-benzylureido) phenyl)-3-chloropyridine-2-carboxylate (31). The compound 31 was purified using column chromatography with EtOAc/Hexane (20:80) as a white solid, $88 \%$ yield; mp 204-207 ${ }^{\circ} \mathrm{C}$; ${ }^{1} \mathrm{H}$ NMR (400 MHz, DMSO): $\delta 9.70(\mathrm{~s}, 1 \mathrm{H}), 8.13(\mathrm{~d}, J=9.2 \mathrm{~Hz}, 1 \mathrm{H}), 7.42$ (m, 1H), $7.32(\mathrm{~m}, 5 \mathrm{H}), 7.23(\mathrm{~m}, 1 \mathrm{H}), 7.09(\mathrm{~m}, 2 \mathrm{H}), 7.03(\mathrm{~m}$, $1 \mathrm{H}), 6.84(\mathrm{~s}, 2 \mathrm{H}), 4.27(\mathrm{~d}, J=6.0 \mathrm{~Hz}, 2 \mathrm{H}), 3.80(\mathrm{~s}, 3 \mathrm{H}) ;{ }^{13} \mathrm{C}$ NMR (75 MHz, DMSO): $\delta$ 165.0, 155.1, 154.7, 153.7, 152.6, 
$150.8,146.3,140.1,138.4,129.2,128.8,127.1,126.7,125.6$, 121.3, 120.5, 111.6, 109.4, 52.5, 42.9; HRMS $m / z: 411.1221$ $[\mathrm{M}+\mathrm{H}]^{+}$calcd for $\mathrm{C}_{21} \mathrm{H}_{19} \mathrm{ClN}_{4} \mathrm{O}_{3}, \mathrm{C}, 61.39 ; \mathrm{H}, 4.66 ; \mathrm{N}$, 13.64; found, C, 62.15; H, 5.03; N, 13.10.

Methyl-4-amino-3-chloro-6-(2-(3-(4-methoxyphenyl) ureido) phenyl) pyridine-2-carboxylate (32). The compound 32 was purified using column chromatography with EtOAc/ Hexane $(60: 40)$ as a white solid, $94 \%$ yield; mp $187-189{ }^{\circ} \mathrm{C}$; ${ }^{1} \mathrm{H}$ NMR (300 MHz, DMSO): $\delta 9.90(\mathrm{~s}, 1 \mathrm{H}), 8.92(\mathrm{~s}, 1 \mathrm{H})$, $8.08(\mathrm{~d}, \mathrm{~J}=8.1 \mathrm{~Hz}, 1 \mathrm{H}), 7.47(\mathrm{~d}, \mathrm{~J}=7.2 \mathrm{~Hz}, 1 \mathrm{H}), 7.35(\mathrm{~m}$, $3 \mathrm{H}), 7.09(\mathrm{~m}, 2 \mathrm{H}), 6.85(\mathrm{~m}, 4 \mathrm{H}), 3.86(\mathrm{~s}, 3 \mathrm{H}), 3.70(\mathrm{~s}, 3 \mathrm{H})$; ${ }^{13} \mathrm{C}$ NMR (75 MHz, DMSO): $\delta$ 165.0, 154.4, 154.4, 152.7, $152.6,146.5,137.8,132.9,129.3,125.9,123.2,121.8,121.1$, $119.8,113.9,111.5,109.3,55.1,52.6$; HRMS $m / z: 427.1170$ $[\mathrm{M}+\mathrm{H}]^{+}$, calcd for $\mathrm{C}_{21} \mathrm{H}_{19} \mathrm{ClN}_{4} \mathrm{O}_{4}, \mathrm{C}, 59.09 ; \mathrm{H}, 4.49 ; \mathrm{N}$, 13.13; found, C, 58.67; H, 4.13; N, 13.84 .

Methyl-4-amino-3-chloro-6-(2-(3-(3-(trifluoromethyl) phenyl) ureido) phenyl) pyridine-2-carboxylate (33). The compound 33 was purified using column chromatography with EtOAc/Hexane (40:60) as an off white solid, 91\% yield; mp 197-200 ${ }^{\circ} \mathrm{C}$; ${ }^{1} \mathrm{H}$ NMR (400 MHz, DMSO): $\delta 10.18$ (s, $1 \mathrm{H}$ ), $9.51(\mathrm{~s}, 1 \mathrm{H}), 8.08(\mathrm{~m}, 1 \mathrm{H}), 7.98(\mathrm{~s}, 1 \mathrm{H}), 7.52(\mathrm{~m}, 3 \mathrm{H}), 7.39$ $(\mathrm{t}, 1 \mathrm{H}), 7.30(\mathrm{~d}, J=7.6 \mathrm{~Hz}, 1 \mathrm{H}), 7.13(\mathrm{~m}, 2 \mathrm{H}), 6.89(\mathrm{~s}, 2 \mathrm{H})$, $3.86(\mathrm{~s}, 3 \mathrm{H}) ;{ }^{13} \mathrm{C}$ NMR (75 MHz, DMSO): $\delta$ 164.9, 154.3, $152.7,152.5,146.4,140.8,137.3,129.9,129.4,128.8,126.2$, $122.5,121.6,117.9,114.0,111.6,109.3,52.6$; HRMS $m / z$ : 465.0935 $[\mathrm{M}+\mathrm{H}]^{+}$calcd for $\mathrm{C}_{21} \mathrm{H}_{16} \mathrm{ClF}_{3} \mathrm{~N}_{4} \mathrm{O}_{3}, \mathrm{C}, 54.26 ; \mathrm{H}$, 3.47; N, 12.05; found, C, 55.03; H, 3.89; N, 11.37 .

Methyl-4-amino-3-chloro-6-(2-(3-(4-(trifluoromethyl) phenyl) ureido) phenyl) pyridine-2-carboxylate (34). The compound 34 was purified using column chromatography with EtOAc/Hexane (40:60) as an off white solid, $85 \%$ yield; mp 185-187 ${ }^{\circ} \mathrm{C}$; ${ }^{1} \mathrm{H}$ NMR (300 MHz, DMSO): $\delta 10.22(\mathrm{~s}, 1 \mathrm{H})$, $9.54(\mathrm{~s}, 1 \mathrm{H}), 8.08(\mathrm{~d}, J=8.3 \mathrm{~Hz}, 1 \mathrm{H}), 7.64(\mathrm{~s}, 4 \mathrm{H}), 7.53(\mathrm{dd}$, $1 \mathrm{H}), 7.39(\mathrm{~m}, 1 \mathrm{H}), 7.17(\mathrm{~s}, 1 \mathrm{H}), 7.13(\mathrm{~m}, 1 \mathrm{H}), 6.87(\mathrm{~s}, 2 \mathrm{H})$, $3.86(\mathrm{~s}, 3 \mathrm{H}) ;{ }^{13} \mathrm{C}$ NMR (75 MHz, DMSO): $\delta$ 167.2, 154.2, $152.7,152.3,143.7,137.2,129.4,128.8,128.2,126.2,126.1$, 126.0, 122.5, 121.4, 117.7, 109.3, 52.6; HRMS $m / z: 465.0783$ $[\mathrm{M}+\mathrm{H}]^{+}$calcd for $\mathrm{C}_{21} \mathrm{H}_{16} \mathrm{ClF}_{3} \mathrm{~N}_{4} \mathrm{O}_{3}, \mathrm{C}, 54.26 ; \mathrm{H}, 3.47 ; \mathrm{N}$, 12.05; found, C, 54.91; $\mathrm{H}, 3.51 ; \mathrm{N}, 11.65$.

Methyl-4-amino-3-chloro-6-(2-(3-(2-chlorophenyl) ureido) phenyl) pyridine-2-carboxylate (35). The compound 35 was purified using column chromatography with EtOAc/ Hexane (15:85) as a white solid, $96 \%$ yield; mp $199-202{ }^{\circ} \mathrm{C}$; ${ }^{1} \mathrm{H}$ NMR (400 MHz, DMSO): $\delta 9.59(\mathrm{~s}, 1 \mathrm{H}), 8.54(\mathrm{~s}, 1 \mathrm{H})$, $8.00(\mathrm{~m}, 2 \mathrm{H}), 7.44(\mathrm{~m}, 2 \mathrm{H}), 7.39(\mathrm{~m}, 1 \mathrm{H}), 7.29(\mathrm{t}, 1 \mathrm{H}), 7.13$ $(\mathrm{m}, 1 \mathrm{H}), 7.06(\mathrm{~m}, 1 \mathrm{H}), 7.04(\mathrm{~m}, 1 \mathrm{H}), 6.83(\mathrm{~s}, 2 \mathrm{H}), 3.84(\mathrm{~s}$, $3 \mathrm{H}) ;{ }^{13} \mathrm{C}$ NMR $(75 \mathrm{MHz}, \mathrm{DMSO}): \delta 165.4,154.3,152.5$, $152.3,147.4,136.6,136.0,129.3,129.1,128.5,127.4,123.7$, $123.1,122.8,122.7,122.2,111.2,110.0,52.5$; HRMS $m / z$ : 431.6323 $[\mathrm{M}+\mathrm{H}]^{+}$calcd for $\mathrm{C}_{20} \mathrm{H}_{16} \mathrm{ClN}_{4} \mathrm{O}_{3}, \mathrm{C}, 60.69 ; \mathrm{H}$, 4.07; N, 14.15; found, C, 61.24; H, 4.33; N, 13.64 .

Methyl-4-amino-3-chloro-6-(2-(3-(4-(methylthio) phenyl) ureido) phenyl) pyridine-2-carboxylate (36). The compound 36 was purified using column chromatography with EtOAc/ Hexane (25:75) as an off white solid, 93\% yield; mp 225-227 ${ }^{\circ} \mathrm{C}$; ${ }^{1} \mathrm{H}$ NMR (300 MHz, DMSO): $\delta 10.02$ (s, 1H), 9.12 (s, $1 \mathrm{H}), 8.08(\mathrm{~d}, J=7.9 \mathrm{~Hz}, 1 \mathrm{H}), 7.49(\mathrm{dd}, 1 \mathrm{H}), 7.41(\mathrm{~d}, J=8.8$ $\mathrm{Hz}, 2 \mathrm{H}), 7.37(\mathrm{~m}, 1 \mathrm{H}), 7.21(\mathrm{~d}, J=8.6 \mathrm{~Hz}, 2 \mathrm{H}), 7.15(\mathrm{~s}, 1 \mathrm{H})$, $7.10(\mathrm{~m}, 1 \mathrm{H}), 6.86(\mathrm{~s}, 2 \mathrm{H}), 3.86(\mathrm{~s}, 3 \mathrm{H}), 2.43(\mathrm{~s}, 3 \mathrm{H}) ;{ }^{13} \mathrm{C}$ NMR (75 MHz, DMSO): $\delta$ 165.0, 154.4, 152.6, 152.4, 146.4, $137.6,129.8,128.8,127.7,126.0,122.0,121.2,118.9,111.6$,
109.3, 52.6, 15.9; HRMS m/z: $443.0937[\mathrm{M}+\mathrm{H}]^{+}$calcd for $\mathrm{C}_{21} \mathrm{H}_{19} \mathrm{ClN}_{4} \mathrm{O}_{3} \mathrm{~S}, \mathrm{C}, 56.95 ; \mathrm{H}, 4.32 ; \mathrm{N}, 12.65 ; \mathrm{S}, 7.24$; found, C, 56.19; H, 4.06; N, 13.34; S, 7.68.

Methyl 6-(2-(3-allylureido) phenyl)-4-amino-3-chloropyridine-2-carboxylate (37). The compound 37 was purified using column chromatography with EtOAc/Hexane (50:50) as an off white solid, $87 \%$ yield; mp $189-192{ }^{\circ} \mathrm{C}$; ${ }^{1} \mathrm{H}$ NMR (400 MHz, DMSO): $\delta 9.66$ (s, 1H), 8.10 (d, $J=7.6 \mathrm{~Hz}, 1 \mathrm{H}), 7.41$ $(\mathrm{m}, 1 \mathrm{H}), 7.31(\mathrm{t}, 1 \mathrm{H}), 7.09(\mathrm{~s}, 1 \mathrm{H}), 7.02(\mathrm{~m}, 1 \mathrm{H}), 6.84(\mathrm{~m}$, $2 \mathrm{H}), 6.26(\mathrm{~m}, 1 \mathrm{H}), 5.83(\mathrm{~m}, 1 \mathrm{H}), 5.15(\mathrm{~m}, 1 \mathrm{H}), 5.05(\mathrm{~m}, 1 \mathrm{H})$, $3.87(\mathrm{~s}, 3 \mathrm{H}), 3.70(\mathrm{~m}, 2 \mathrm{H}) ;{ }^{13} \mathrm{C}$ NMR (75 MHz, DMSO): $\delta$ $155.8,155.5,151.9,140.1,135.5,130.6,127.9$, 122.1, 121.4, $120.9,115.7,109.0,53.2,42.7$; HRMS $m / z: 361.0355[\mathrm{M}+$ $\mathrm{H}]^{+}$calcd for $\mathrm{C}_{17} \mathrm{H}_{17} \mathrm{ClN}_{4} \mathrm{O}_{3}, \mathrm{C}, 56.59 ; \mathrm{H}, 4.75 ; \mathrm{N}, 15.53$; found, C, 55.89; H, 4.27; N, 16.19.

\section{ASSOCIATED CONTENT}

\section{Supporting Information}

The Supporting Information is available free of charge at https://pubs.acs.org/doi/10.1021/acsomega.0c05690.

In vitro anti-tubercular activity determination, nutrient starvation assay model, cytotoxicity determination, molecular docking studies, X-ray refinement data, and spectral data for all 8-37 and derivatives (PDF)

Crystallographic information data for 15, CCDC 2027737 (CIF)

Crystallographic information data for 18, CCDC 2027738 (CIF)

\section{AUTHOR INFORMATION}

\section{Corresponding Author}

Koya Prabhakara Rao - New Generation Materials Lab (NGML), Department of Science and Humanities, Vignan's Foundation for Science Technology and Research (VFSTR) (Deemed to be University), Guntur 522 213, Andhra Pradesh, India; O orcid.org/0000-0001-6077-5746; Email: drkpr_sh@vignan.ac.in, kprao2005@gmail.com

\section{Authors}

Srihari Konduri - New Generation Materials Lab (NGML), Department of Science and Humanities, Vignan's Foundation for Science Technology and Research (VFSTR) (Deemed to be University), Guntur 522 213, Andhra Pradesh, India; (1) orcid.org/0000-0003-1618-3932

Dodda Bhargavi - New Generation Materials Lab (NGML), Department of Science and Humanities, Vignan's Foundation for Science Technology and Research (VFSTR) (Deemed to be University), Guntur 522 213, Andhra Pradesh, India

Jyothi Prashanth - Department of Physics, Kakatiya University, Warangal 506009, Telangana, India

Vagolu Siva Krishna - Department of Pharmacy, Birla Institute of Technology \& Amp; Science-Pilani, Hyderabad 500 078, India

Dharmarajan Sriram - Department of Pharmacy, Birla Institute of Technology \& Amp; Science-Pilani, Hyderabad 500 078, India

Complete contact information is available at:

https://pubs.acs.org/10.1021/acsomega.0c05690

\section{Notes}

The authors declare no competing financial interest. 


\section{ACKNOWLEDGMENTS}

K.P.R. acknowledges DST-SERB, for financial support grant no: EMR/2014/001114, for early career award.

\section{REFERENCES}

(1) Rosemeyer, H. The chemodiversity of purine as a constituent of natural products. Chem. Biodiversity 2004, 1, 361-401.

(2) World Health Organization Global Tuberculosis Report, 2016.

(3) Crespo, R. A.; Dang, Q.; Zhou, N. E.; Guthrie, L. M.; Snavely, T. C.; Dong, W.; Loesch, K. A.; Suzuki, T.; You, L.; Wang, W.; et al. Structure-guided drug design of 6-substituted adenosine analogues as potent inhibitors of mycobacterium tuberculosis adenosine kinase. J. Med. Chem. 2019, 62, 4483-4499.

(4) Ackermann, L.; Potukuchi, H. K. Regioselective syntheses of fully-substituted 1,2,3-triazoles: the $\mathrm{CuAAC} / \mathrm{C}-\mathrm{H}$ bond functionalization nexus. Org. Biomol. Chem. 2010, 8, 4503-4513.

(5) Biava, M.; Porretta, G. C.; Poce, G.; De Logu, A.; Saddi, M.; Meleddu, R.; Manetti, F.; De Rossi, E.; Botta, M. 1,5-diphenylpyrrole derivatives as antimycobacterial agents. Probing the influence on antimycobacterial activity of lipophilic substituents at the phenyl rings. J. Med. Chem. 2008, 51, 3644-3648.

(6) Kamal, A.; Hussaini, S. M. A.; Faazil, S.; Poornachandra, Y.; Narender Reddy, G.; Kumar, C. G.; Rajput, V. S.; Rani, C.; Sharma, R.; Khan, I. A.; et al. Anti-tubercular agents. Part 8: synthesis, antibacterial and antitubercular activity of 5-nitrofuran based 1,2,3triazoles. Bioorg. Med. Chem. Lett. 2013, 23, 6842-6846.

(7) Kavitha, M.; Kumar, G. S.; Amanda, L. H.; Elizabeth, S. M.; Minjia, Z.; Rao, S. N.; Deviprasad, R. G.; Barbara, J. M.; Joanna, B. G.; Gregory, D. C.; et al. Repurposing cryptosporidium inosine $5^{\prime}$ monophosphate dehydrogenase inhibitors as potential antibacterial agents. ACS Med. Chem. Lett. 2014, 5, 846-850.

(8) Konduri, S.; Prashanth, J.; Krishna, V. S.; Sriram, D.; Behera, J. N.; Siegel, D.; Rao, K. P. Design and synthesis of purine connected piperazine derivatives as novel inhibitors of mycobacterium tuberculosis. Bioorg. Med. Chem. Lett. 2020, 30, 127512.

(9) Bellina, F.; Rossi, R. Synthesis and biological activity of pyrrole, pyrroline and pyrrolidine derivatives with two aryl groups on adjacent positions. Tetrahedron 2006, 62, 7213-7256.

(10) Lauria, A.; Delisi, R.; Mingoia, F.; Terenzi, A.; Martorana, A.; Barone, G.; Almerico, A. M. 1,2,3-Triazole in heterocyclic compounds, endowed with biological activity, through 1,3-dipolar cycloadditions. Eur. J. Org. Chem. 2014, 16, 3289-3306.

(11) von Groote-Bidlingmaier, F.-V.; Patientia, R.; Sanchez, E.; Balanag, V., Jr.; Ticona, E.; Segura, P.; Cadena, E.; Yu, C.; Cirule, A.; Lizarbe, V.; et al. Efficacy and safety of delamanid in combination with an optimised background regimen for treatment of multidrugresistant tuberculosis: a multicentre, randomised, double-blind, placebo-controlled, parallel group phase 3 trial. Lancet Respir. Med. 2019, 7, 249-259.

(12) Zhang, M.-Z.; Chen, Q.; Yang, G.-F. A review on recent developments of indole-containing antiviral agents. Eur. J. Med. Chem. 2015, 89, 421-441.

(13) Tripathi, A. C.; Gupta, S. J.; Fatima, G. N.; Sonar, P. K.; Verma, A.; Saraf, S. K. 4-Thiazolidinones: The advances continue. Eur. J. Med. Chem. 2014, 72, 52.

(14) Baizer, M. M.; Dub, M.; Gister, S.; Steinberg, N. G. Synthesis of isoniazid from citric acid. J. Am. Pharm. Assoc. 1956, 45, 478-480.

(15) Quemard, A.; Laneelle, G.; Lacave, C. Mycolic acid synthesis: A target for ethionamide in mycobacteria? Antimicrob. Agents Chemother. 1992, 36, 1316-1321.

(16) Johnson, P. L.; Renga, J. M.; Galliford, C. V.; Whiteker, G. T.; Giampietro, N. C. Org. Lett. 2015, 17, 2905-2907.

(17) Epp, J. B.; Alexander, A. L.; Balko, T. W.; Buysse, A. M.; Brewster, W. K.; Bryan, K.; Daeuble, J. F.; Fields, S. C.; Gast, R. E.; Green, R. A.; et al. The discovery of arylex active and rinskor active: Two novel auxin herbicides. Bioorg. Med. Chem. 2016, 24, 362-371.

(18) Whiteker, G. T.; Froese, R. D. J.; Arndt, K. E.; Renga, J. M.; Zhu, Y.; Roth, G. A.; Yang, Q.; Canturk, B.; Klosin, J. Synthesis of 6-
Aryl-5-fluoropicolinate herbicides via halex reaction of tetrachloropicolinonitrile. Org. Process Res. Dev. 2019, 23, 2166-2174.

(19) Srinivas, B.; Suryachandram, J.; Katyayani Devi, Y.; Prabhakara Rao, K. Synthesis and antibacterial activity studies of 8,9-dihydro [7h] benzo 1,2,4-oxadiazoles and its coumarin derivatives. J. Heterocycl. Chem. 2017, 54, 3730-3734.

(20) Srinivas, B.; Jyothi, P.; Rao, M. V. B.; Rao, K. P. Design and synthesis of antimicrobial active (E)-(3-(Substituted-styryl)-7H-furo[2,3-f]chromen-2-yl)(phenyl)methanone derivatives and their in silico molecular docking studies. J. Heterocycl. Chem. 2019, 56, 73-80.

(21) Suman, K.; Prashanth, J.; Rao, K. P.; Subramanyam, M.; Anuradha, V.; Rao, M. V. B. Facile synthesis of 6-phenyl-6h-chromeno [4, 3-b] quinoline derivatives using $\mathrm{NaSO}_{4} @ \mathrm{SiO}_{2}$ re-useable catalyst and their antibacterial activity study correlated by molecular docking studies. Lett. Drug Des. Discovery 2020, 17, 929-938.

(22) Subramanyam, M.; Sreenivasulu, R.; Gundla, R.; Rao, M. V. B.; Rao, K. P. Synthesis, biological evaluation and docking studies of 1,3,4-oxadiazole fused benzothiazole derivatives for anticancer drugs. Lett. Drug Des. Discovery 2018, 15, 1299-1307.

(23) Rao, K. P.; Kusamoto, T.; Toshimitsu, F.; Inayoshi, K.; Kume, S.; Sakamoto, R.; Nishihara, H.; Nishihara, H. Double protonation of 1,5-bis(triarylaminoethynyl)anthraquinone to form a paramagnetic pentacyclic dipyrylium salt. J. Am. Chem. Soc. 2010, 132, 1247212479.

(24) Rao, K. P.; Kondo, M.; Sakamoto, R.; Kusamoto, T.; Nishikawa, M.; Kume, S.; Nihei, M.; Oshio, H.; Nishihara, H. Benzo[e]pyrene skeleton dipyryliumdication with a strong donoracceptor-donor interaction, and its two-electron reduced molecule. Chem.-Eur. J. 2011, 17, 14010-14019.

(25) Sakamoto, R.; Rao, K. P.; Nishihara, H. Arylethynylanthraquinone and bis(arylethynyl)anthraquinone:strongdonoracceptor interaction and proton-induced cyclization to form pyrylium and dipyrylium salts. Chem. Lett. 2011, 40, 1316-1326.

(26) Rao, K. P.; Kondo, M.; Sakamoto, R.; Kusamoto, T.; Kume, S.; Nishihara, H. Protonation-induced cyclization of 1,8-bis(diarylethynyl) anthraquinones: monopyrylium salt formation and intensification of donor-acceptor interaction. Chem. Lett. 2011, 40, $1456-1458$.

(27) Marzi, E.; Bigi, A.; Schlosser, M. Strategies for the selective functionalization of dichloropyridines at various sites. Eur. J. Org. Chem. 2001, 2001, 1371-1376.

(28) Fields, S. C.; Alexander, A. L.; Balko, T. W.; Bjelk, L. A.; Buysse, A. M.; Keese, R. J.; Krumel, K. L.; Lo, W. C.-L.; Lowe, C. T.; Richburg, J. S., III et al. 4-aminopicolinates and their use as herbicides U.S. Patent 6,297,197 B1, (Oct 2, 2001).

(29) Brünjes, M.; Döller, U.; Dietrich, H.; Hoffmann, M. G.; Isolde, H.-H.; Rosinger, C. H.; Elmar, G.; Ines, H. 6-(2-Aminophenyl)picolinates and their use as herbicides U.S. Patent 2,013,326,735 A1, Dec 5, 2013.

(30) Renuka, J.; Reddy, K. I.; Srihari, K.; Jeankumar, V. U.; Shravan, M.; Sridevi, J. P.; Yogeeswari, P.; Babu, K. S.; Sriram, D. Design, synthesis, biological evaluation of substituted benzofurans as DNA gyraseB inhibitors of Mycobacterium tuberculosis. Bioorg. Med. Chem. 2014, 22, 4924-4934.

(31) Deepak, K.; Garima, K.; Saqib, K.; Anil, K. T.; Ramandeep, S.; Diwan, S. R. Synthesis of novel 1,2,3-triazole derivatives of isoniazid and their in vitro and in vivo antimycobacterial activity evaluation. Eur. J. Med. Chem. 2014, 81, 301-313.

(32) Franzblau, S. G.; Witzig, R. S.; McLaughlin, J. C.; Torres, P.; Madico, G.; Hernandez, A.; Degnan, M. T.; Cook, M. B.; Quenzer, V. K.; Ferguson, R. M.; et al. Rapid, low-technology MIC determination with clinical mycobacterium tuberculosis isolates by using the microplate alamar blue assay. J. Clin. Microbiol. 1998, 36, 362-366.

(33) Wilcken, R.; Zimmermann, M. O.; Lange, A.; Joerger, A. C.; Boeckler, F. M. Principles and applications of halogen bonding in medicinal chemistry and chemical biology. J. Med. Chem. 2013, 56, 1363-1388.

(34) Collins, L.; Franzblau, S. G. Microplate Alamar blue assay versus BACTEC 460 system for high-throughput screening of 
compounds against Mycobacterium tuberculosis and Mycobacterium avium. Antimicrob. Agents Chemother. 1997, 41, 1004-1009.

(35) Betts, J. C.; Lukey, P. T.; Robb, L. C.; McAdam, R. A.; Duncan, $\mathrm{K}$. Evaluation of a nutrient starvation model of Mycobacterium tuberculosis persistence by gene and protein expression profiling. Mol. Microbiol. 2002, 43, 717-731.

(36) Malapati, P.; Krishna, V. S.; Nallangi, R.; Srilakshmi, R. R.; Sriram, D. Identification and development of benzoxazole derivatives as novel bacterial glutamate racemase inhibitors. Eur. J. Med. Chem. 2018, 145, 23-34.

(37) Reck, F.; Alm, R. A.; Brassil, P.; Newman, J. V.; Ciaccio, P.; McNulty, J.; Barthlow, H.; Goteti, K.; Breen, J.; Comita-Prevoir, J.; et al. Novel $\mathrm{N}$-linked aminopiperidine inhibitors of bacterial topoisomerase type II with reduced pKa: antibacterial agents with an improved safety profile. J. Med. Chem. 2012, 55, 6916-6933.

(38) Frisch, M. J.; Trucks, G. W.; Schlegel, H. B.; Scuseria, G. E.; Robb, M. A.; Cheeseman, J. R.; Scalmani, G.; Barone, V.; Petersson, G. A.; Nakatsuji, H. et al. Gaussian 09, Revision D.01; Gaussian, Inc., Wallingford CT, 2009.

(39) Farmer, B. T.; Constantine, K. L.; Goldfarb, V.; Friedrichs, M. S.; Wittekind, M.; Yanchunas, J.; Robertson, J. G.; Mueller, L. Localizing the $\mathrm{NADP}^{+}$binding site on the MurB enzyme by NMR. Nat. Struct. Biol. 1996, 3, 995-997.

(40) Accelrys Software Inc. Discovery Studio Modeling Environment, Release 4.1.0; Accelrys Software Inc.: San Diego, Calif, USA, 2013. 